\title{
Earthquakes Reconnaissance Data Sources, a Literature Review
}

\author{
Diana Contreras ${ }^{1,2}$, Sean Wilkinson ${ }^{3}$ and Philip James ${ }^{4}$
}

\author{
1 Newcastle University; diana.contreras-mojica@newcastle.ac.uk \\ 2 Cardiff University; contrerasmojicad@cardiff.ac.uk ${ }^{3}$ \\ 3 Newcastle University; sean.wilkinson@newcastle.ac.uk \\ 4 Newcastle University; philip.james@ncl.ac.uk \\ * Correspondence: diana.contreras-mojica@newcastle.ac.uk; Tel.: (+44 (0) 191208 4407)
}

\begin{abstract}
Earthquakes are one of the most catastrophic natural phenomena. After an earthquake, earthquake reconnaissance enables effective recovery by collecting building damage data and other impacts. This paper aims to identify state-of-the-art data sources for building damage assessment and provide guidance for more efficient data collection. We have reviewed 38 articles that indicate the sources used by different authors to collect data related to damage and post-disaster recovery progress after earthquakes between 2014 and 2021. The current data collection methods have been grouped into seven categories: fieldwork or ground surveys, omnidirectional imagery (OD), terrestrial laser scanning (TLS), remote sensing (RS), crowdsourcing platforms, social media (SM) and closed-circuit television videos (CCTV). The selection of a particular data source or collection technique for earthquake reconnaissance includes different criteria depending on what question are to be answered by this data. We conclude that modern reconnaissance mission can not rely on a single data source, and that different data sources should complement each other, validate collected data, or systematically quantify the damage. The recent increase in the number of crowdsourcing and SM platforms used to source earthquake reconnaissance data demonstrates that this is likely to become an increasingly important source of data.
\end{abstract}

Keywords: Earthquake reconnaissance; fieldwork surveys; closed-circuit television videos (CCTV); remote sensing (RS), crowdsourcing platforms and Social Media (SM).

\section{Introduction}

Each year, disasters cause significant human and economic losses. Out of these disasters, earthquakes are one of the most catastrophic natural phenomena. These events have caused more than 23 million deaths between 1902 and 2011 [1], substantial physical, social, and economic [2], and occasionally institutional, cultural and environmental losses. Following an earthquake, there is a substantial demand and need for spatial information $[1,2]$ about population location [3], evacuation routes, availability of resources [4], size of the affected area and distribution of damage. Later, during the emergency phase, it is necessary to collect more detailed data about damages in the structural components of buildings [5].

Earthquake reconnaissance enables collecting perishable data on building performance to prepare statistics, calibrate and validate engineering models, and identify the construction deficiencies that lead to inadequate structural performance. This paper aims to identify state-of-the-art data sources for building damage assessment and serve as a guide to make more efficient data collection based on the experiences in the last years. Damage is understood as a change in the mechanical, material and/or geometric properties of a building, affecting its performance and behaviour [6]. Damage data is highly 
'perishable' or ephemeral since damaged structures may be altered or removed during rescue or early recovery [7] activities [8] or modified by aftershocks. A large earthquake produces extensive building damage and affects the operational conditions of other structures [9] in and around an urban area [10]. Additionally, economic and social consequences are usually related to loss of buildings usability [11, 12]. Buildings are essential places to live [13], to do business or to carry out activities [14]; this is the reason why most of the losses [15] and 75\% of the casualties [16] in disasters are due to building damage [15]. Building damage assessment is a critical activity to secure the safety of the public [5] and provide information for disaster relief, early recovery planning [10] and later reconstruction [17-19], especially due to the threat of aftershocks. Moreover, damage assessment is essential for assessing disasters' social and economic impact [18, 20]. The effectiveness of post-disaster activities during the response and recovery phases depends on accurate and early damage estimation [21].

In the past, conventional recording and measurement tools, such as photography, note-taking and surveying, were used by reconnaissance investigators to collect data and document field observations. Nowadays, the availability of state-of-the-art instrumentation, mobile data collection technologies, social media (SM), crowdsourcing platforms, training and field support services has increased the ability of field investigation teams to capture perishable data during post-disaster phases [8]. Currently, there are two data sources in the disaster management cycle: sensor-generated such as the data collected by remotes sensing (RS) tools, closed-circuit television videos (CCTV) or satellites and usergenerated content collected from SM and crowdsourcing platforms [22, 23]. Quantitative assessment of damage determines the physical damage of the exposed elements in the affected area. The result of the damage assessment will be the aggregate quantities of damages for an exposure unit. This quantitative assessment is used to assess the direct economic loss as the basis for calculating the value of economic losses: the replacement cost [18] or insurance payouts of value to international aid organisations, bi-lateral/multilateral donors and the insurance industry [24]. During the emergency or relief phase, the quantitative assessment of damage starts with the structural component of the buildings due to its essential role in the safety of the population affected by earthquakes, and the estimation of temporary shelter needed [7]. Structural damage evaluation implies a visual inspection to establish whether the building structure components are damaged, the degree to which different elements may be damaged, and the degree of damage represents a risk to the occupants of the building. These data are necessary for understanding the trend of natural disaster impacts and existing planning and building practices [25]. Earthquake reconnaissance enables collecting perishable data on building performance to prepare statistics, calibrate and validate engineering models, and identify the construction deficiencies that lead to inadequate structural performance [26]. Damage detection and characterization involve five closely related subjects [9], i.e., structural health monitoring (SHM), condition monitoring (CM), non-destructive evaluation (NDE), statistical process control (SPC) and damage prognosis (DP) [6].

This paper is divided into five sections. The introduction includes a brief background on the topic of earthquake reconnaissance and data sources over time. The second section, on methods, elaborates on the criteria for selecting the articles that comprise the literature review. The third section focuses on the results, including the data sources identified through the literature review. The fourth section discusses the interaction of data sources identified, and the fifth section contains the conclusions.

\section{Materials and Methods}

A literature review was conducted to identify state-of-the-art data sources for earthquake reconnaissance. Peer-reviewed research articles included in this literature review 
were identified from the Web of Science and in the framework of the project: Learning from Earthquakes United Kingdom (LfE-UK), a joint project undertaken by Newcastle University, the University College of London (UCL) and Cambridge University. Considering that we are interested in state-of-the-art, we focused on publications made in the last five years. The search was conducted between February 2019 and June 2021. In the literature review undertaken at the beginning of the project, we reviewed references published between 2014 and 2019. At the end of the project, we reviewed references published between 2016 to 2021. Eventually, this literature review included references published between 2014 and 2021, the last seven years. According to their relevance, older references were reviewed only when referred by the authors of identified references; however, we have not counted them among the total number of references reviewed because we want to highlight only the most contemporary data sources. Although the main focus was data sources for earthquake reconnaissance, data sources for damages assessment after other natural phenomena or anthropogenic events were reviewed but not counted in the review. The flow diagram of the methodology applied is depicted in Figure 1.

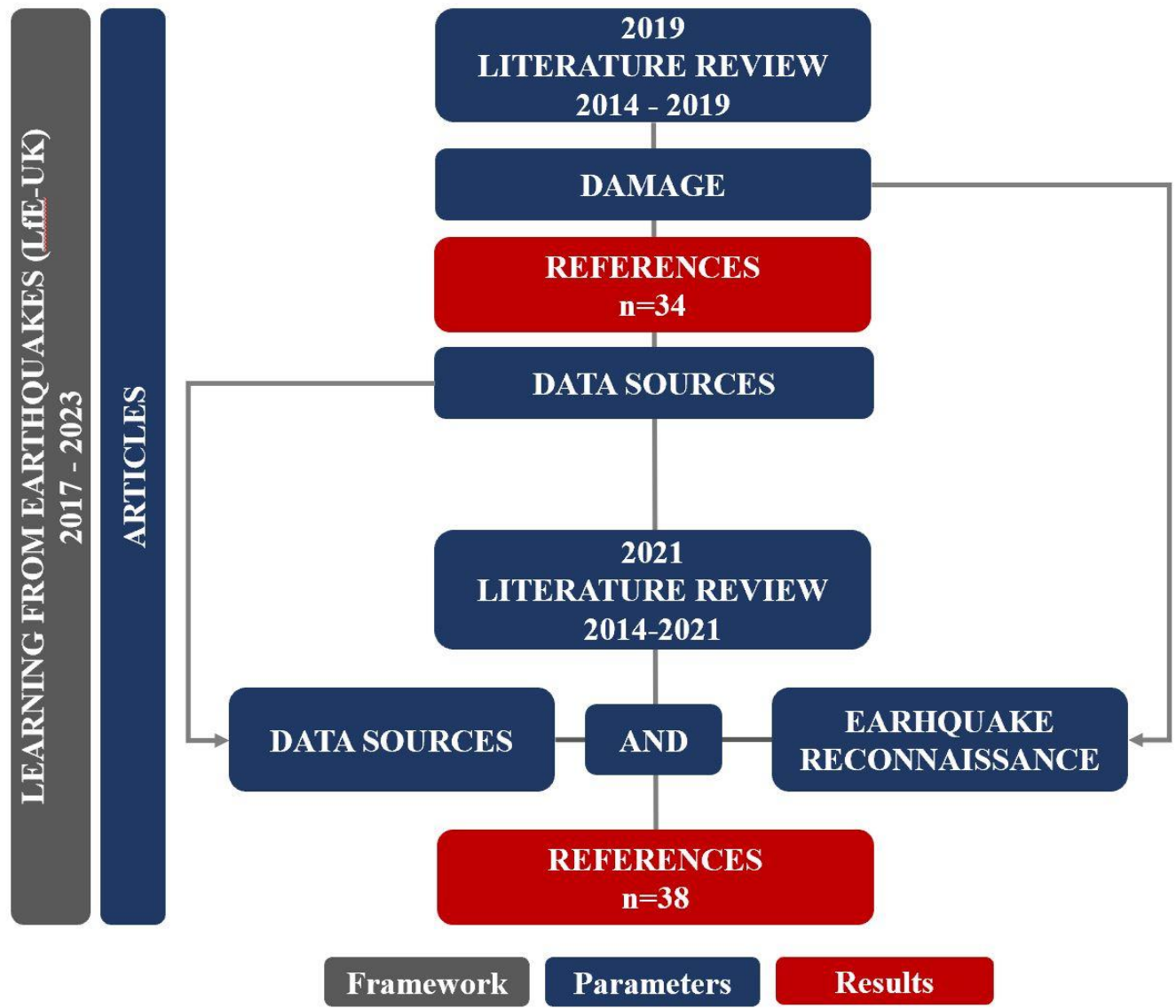

Figure 1. Flow diagram of the methodology applied to select the references for the literature review.

\section{Results}

This paper reviews more than 38 articles that indicate the sources used by different authors to collect data related to damages and post-disaster recovery progress after earthquakes between 2014 and 2021. The data collection sources and methods identified in our literature review have been grouped into seven categories: fieldwork or ground surveys, omnidirectional imagery (OD), terrestrial laser scanning (TLS), RS, crowdsourcing and SM platforms, and CCTV. In the case of RS, we identified six sources: satellite images, unmanned aerial vehicles (UAVs) and small unmanned aerial vehicles (sUAV), light detection and ranging (LiDAR), high-resolution synthetic aperture radar (SAR), 
interferometric synthetic-aperture radar (InSAR), real aperture radar (RAR). We identified seven crowdsourcing platforms: did you feel it (DYFI), Earthquake network, LastQuake, MyShake, Raspberry Shake, QuickDeform and the Taiwan Scientific Earthquake Reporting (TSER) System. We identified three SM platforms as data sources for earthquake reconnaissance: Earthquake network, Facebook and Twitter. The schematic graph of the sources identified is depicted in Figure 2 and the summary of the references reviewed is listed in Table 2.

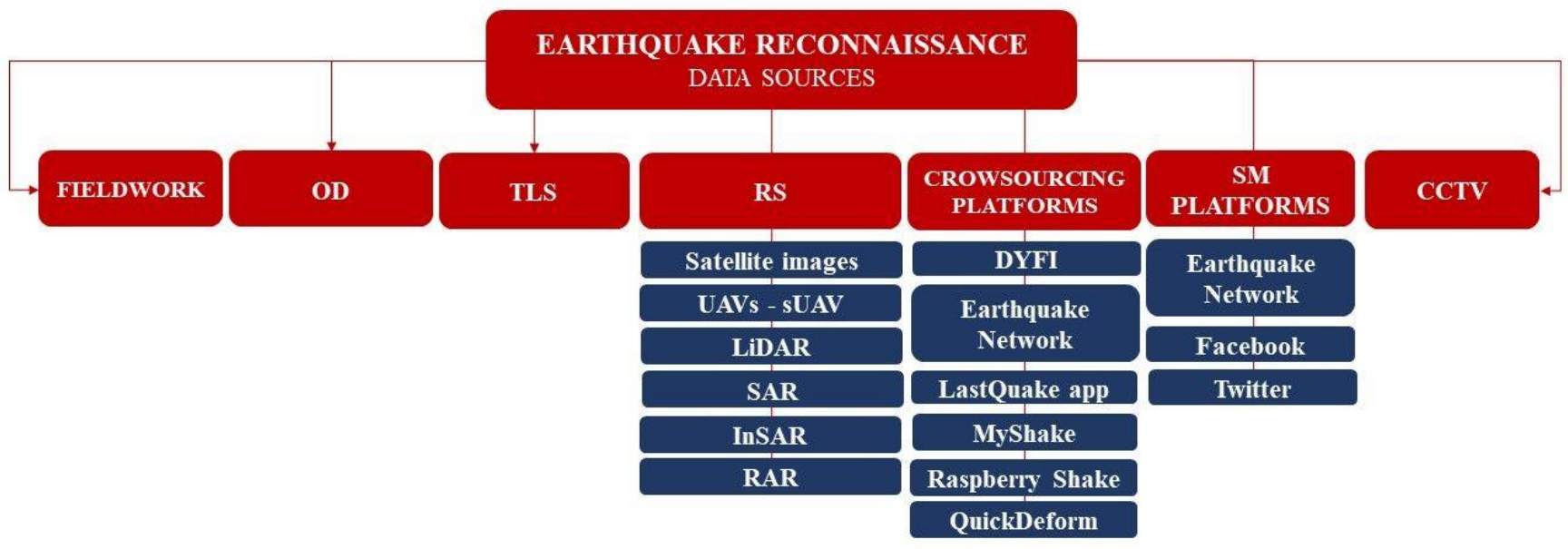

Figure 2. Earthquake reconnaissance data sources.

Table 2. Summary of references reviewed for this literature review.

\begin{tabular}{lll}
\hline \multicolumn{1}{c}{ Data sources } & \multicolumn{1}{c}{ References } \\
\hline Fieldwork or ground surveys & & {$[27],[28],[29],[8],[30],[21],[31],[32],[33]$} \\
\hline Omnidirectional imagery (OD) & & {$[34]$} \\
\hline Terrestrial laser scanning (TLS) & & {$[35]$} \\
\hline & Satellite images & {$[36],[18]$} \\
& UAVs \& sUAV & {$[21],[37],[38]$} \\
Remote sensing (RS) & LiDAR & {$[25]$} \\
& SAR & {$[10],[39]$} \\
& InSAR & {$[40],[41],[42],[43]$} \\
& RAR & {$[6]$} \\
\hline & DYFI & {$[44]$} \\
Crowdsourcing platforms & Earthquake network & {$[45]$} \\
& LastQuake & {$[16,46]$} \\
& MyShake & {$[47]$} \\
Social media (SM) platforms & Raspberry Shake & {$[48]$} \\
& QuickDeform & {$[49]$} \\
& TSER System & {$[50]$} \\
\hline
\end{tabular}

Missions deployed, or missions that have had their results published during the period covered by this literature review are Albania [46, 57], Puerto Rico [44, 45], Mayotte [51], Mexico [27-29], Palu - North Sulawesi (Indonesia) [52, 55, 58], Hualien (China) [50], 
Central Italy [31, 32, 34, 59], Muisne (Ecuador) [34], Nepal [15, 39, 48], Napa - California (USA) [53, 54], Haiti [10] and L'Aquila (Italy) [12, 36]. The location of major earthquakes epicentres from $2014-2019$ included as case studies in this literature review is depicted in Figure 3.

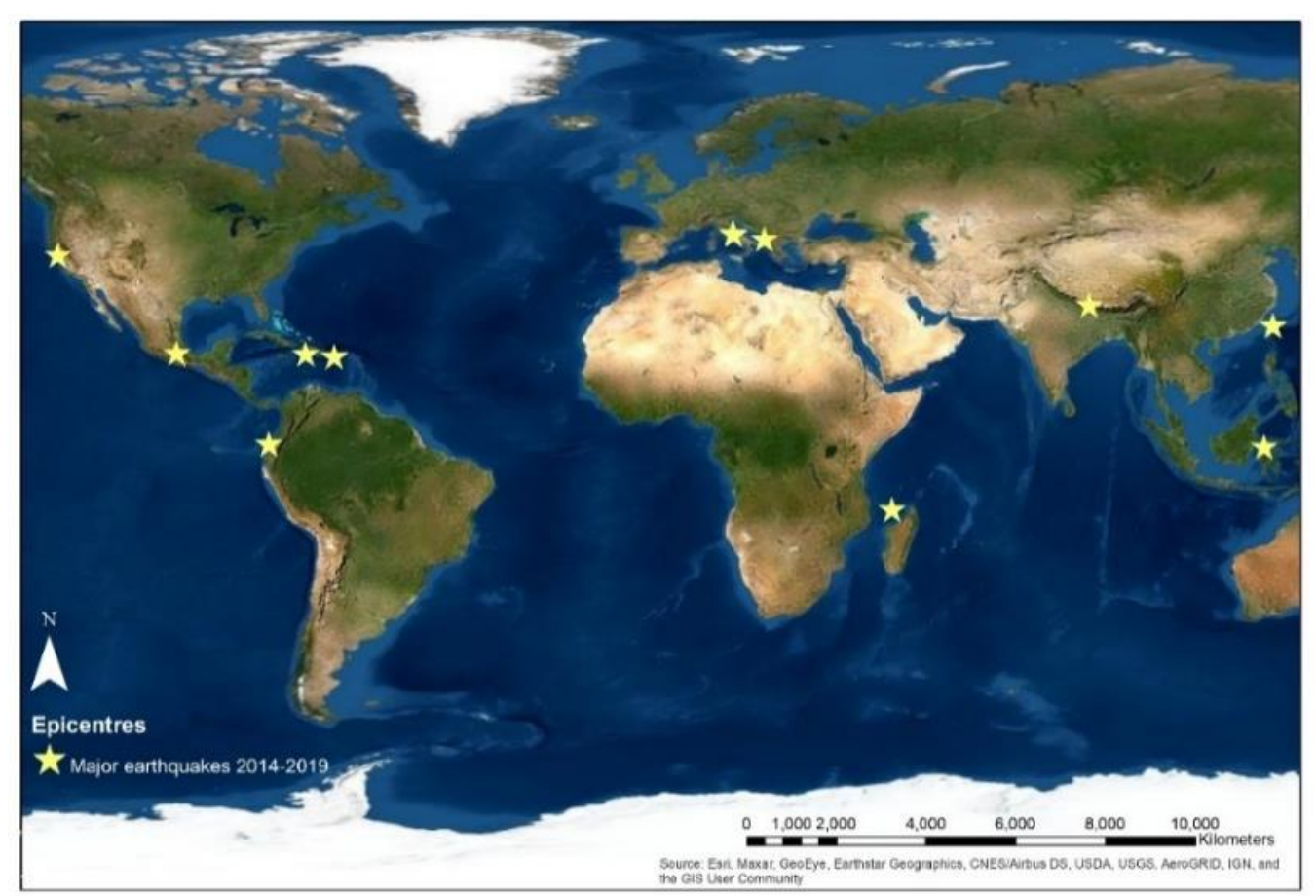

Figure 3. Spatial distribution of epicentres of major earthquakes occurred from 2014 - 2019.

\subsection{Fieldwork or ground surveys}

Post-disaster structural damage assessment is typically based on ground surveying methods [21]. The objective of these missions is to learn about the performance of infrastructure and structures under seismic loading, collecting accurate damage data [34] for further research [28], and scientific understanding of their physical, socio-economic, environmental [8], cultural and institutional consequences. In-situ structural observations sometimes include records not limited to the mechanism of structural failure and observations of undamaged structures and the extend and scale of damage to structures at a global and component level [34]. To develop a detailed building damage map after an earthquake or a hurricane, it is necessary to identify the damage using a building-bybuilding approach [10,52]; most building damage assessments reviewed relied on a footon-ground approach [60]. This detailed inspection is the most reliable [21] and generates invaluable information on the seismic performance of the affected building stock [30]. However, the limited time the mission is deployed and the street level constraints on the extent of observations make it less reliable at collating damage statistics, which are particularly important for validating and developing fragility and vulnerability functions [34].

Fieldwork or ground surveys are a traditional approach to estimate the spatial distribution of earthquake impacts to building clusters, performed by volunteer groups consisting of structural engineers, architects, researchers with experience in building instrumentation, geotechnical and seismological specialists [28] and undergraduate students of these fields. These missions collect structural, geotechnical, seismological and damage information [28]. Earthquake reconnaissance missions are undertaken by national or international organisations such as the Earthquake Engineering Field Investigation Team (EEFIT) $[8,26,34,57,61,62]$ in the United Kingdom (UK), the Geotechnical Extreme Events Reconnaissance Association (GEER) [8, 26, 31, 32, 61, 63], and Earthquake Engineering Research Institute (EERI) $[8,31,34]$ in the United States (US). The EERI, through its 
program Learning from Earthquakes (LFE) established in 1973 was the first professional organization to organize reconnaissance missions to significant seismic events. This organization recently has formed a virtual earthquake reconnaissance teams (VERT) to conduct 'virtual' (i.e., not on-site) assessment within 48 hours after an earthquake [8]. In Italy, the European Centre for Training and Research in Earthquake Engineering (EUCENTRE) and the Italian Network of University Laboratories for Earthquake Engineering (ReLUIS) have organized earthquake reconnaissance missions and conducted follow-on seismic policy analyses. For six decades, the New Zealand Society for Earthquake Engineering (NZSEE) has supported reconnaissance research of earthquakes and major tsunamis in the world [8]. The Asian Technical Committee (ATC3) 'Geotechnology for natural hazards', the Building Research Institute of Japan and the Nepalese Engineering Society has conducted reconnaissance missions in Asia after natural phenomena. Another organization that have supported reconnaissance missions in US is the American Society of Civil Engineers (ASCE). Additionally, sometimes, self-organized teams with a focused-hypothesis driven research question or inquiry are formed to collect data [8]. In the 2017 PueblaMorelos earthquake case, also known as the 2017 Puebla earthquake or the 2017 Mexico earthquake, the Applied Technology Council (ATC) from US deployed a team to Mexico City sponsored by the ATC Endowment Fund. This team was joined by practising architects, engineers, professors and local agencies [28]. The NZSEE, in collaboration with the Universidad Autonoma de Metropolitana (UAM) Azcapotzalco, the American Concrete Institute (ACI) Disaster Reconnaissance team, the Colegio de Ingenieros Civiles de Mexico (CICM) and the team of the Stanford's John A. Blume Earthquake Engineering Centre as well [27] all deployed a team for the same earthquake in Mexico [29].

In a foot-on-ground survey, as it is portrayed in Figure 4, the assessment is conducted manually [33], one building after another [25]; each reconnaissance mission in the field takes approximately one week. Considering that there is a preliminary data collection to limit the inspection area where the causes of failures of buildings can be observed within a safe environment. Earthquake reconnaissance missions members are usually trained volunteers affiliated with one of the organisations mentioned before who cannot spend more than one week far from their daily business. Even the ATC's reconnaissance mission after the 2017 Puebla-Morelos earthquake lasted three days [28]. To maximize the area to inspect, three teams from three to four structural engineers were deployed each day in this specific mission. Each team involved at least one Spanish speaker to interact with residents and one local structural engineer [28]. Usually, preliminary data collection before fieldwork includes seismic information, size of the affected area, building typologies, injuries and casualties, local institutions, accessibility, safety and security aspects, local traditions, and any information supporting the fieldwork planning [31]. Traditionally paper forms were used, but increasingly, smart technologies are used as tools to complete investigation forms and collect multi-media data (e.g. photos, audios and videos) [33]. One example was the damage assessment app used by the EEFIT mission team deployed to Albania to collect damage data after the earthquake in 2019 [57]. The ATC reconnaissance mission for the 2017 Puebla-Morelos earthquake focused not only on buildings with significant but also minimal damage. No inspections were undertaken on collapsed buildings, considering that those buildings do not suggest where or why the failures occurred [28]. This ATC's reconnaissance mission collected damage and geotechnical data, earthquake ground motions from several suites and ambient vibration recordings from buildings instrumented by the team during the reconnaissance trip [28]. This ATC mission instrumented seven of the inspected buildings with an array of accelerometers [28]. The NZSEE and UAM team focused on extensive and widespread damage where local site effects could have contributed to the significant damage in buildings. At the same time, that evaluated the performance of the repaired and retrofitted buildings after the 1985 Michoacan earthquake [29]. Stanford's John A. Blume Earthquake Engineering Centre surveyed the affected area in Mexico from the $24^{\text {th }}$ to the $29^{\text {th }}$ September. It complemented the database of collapsed buildings with data collected from newspapers and SM until the $1^{\text {st }}$ November 2017 [27]. 


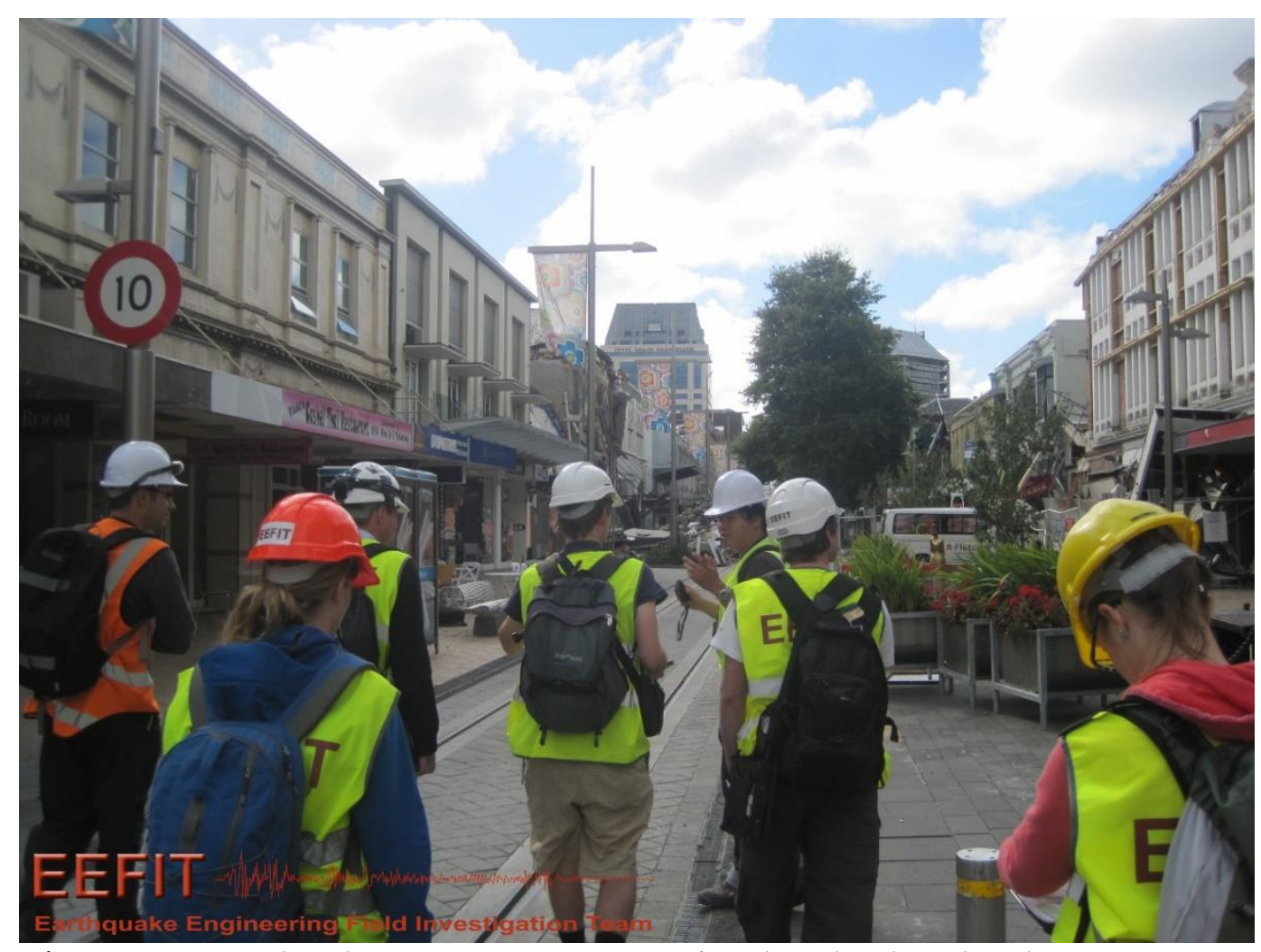

Figure 4. EEFIT earthquake reconnaissance mission after Christchurch earthquake in 2011. Source: [64].

The GEER deployed two teams in Central Italy. The first team integrated entirely by Italians located potential landslides sites of interest. Later, a second-team was deployed to collect data in the identified places by the first team [31]. Manual inspection and documentation of landslides were done by the GEER team in central Italy using standard geologist's tools: scale, measuring tape, clinometer, compass, rock hammers and total station. Key landslide dimensions were measured on each manually inspected point, i.e., length, wide, scarp heigh, and slope inclination [31]. Notes were taken about the slide mass or rockfall constituent materials, local geology, observed groundwater and seepage conditions, and anthropogenic activity in the area. The width and height of the rockfall source were measured using total stations, while slope inclination below the rock source was either estimated or measured [31]. The geologic hammer was utilized to infer the rock strength. Stratification, weathering, spacing, joint width and infill material were evaluated. Distances were estimated for most rock falls, given that lateral and vertical distances of the rollout were too large to measure manually. Boulder fragments were inspected with measurements of boulder size [31]. Parallel to the GEER mission and with its support during the planning phase and the support of the Italian Department of Civil Protection (DPC by its acronym in Italian), EERI, EUCENTRE, and ReLuis also deployed a mission in Central Italy to study the effects of the earthquake sequence not only on the built environment but also on the communities located in the affected areas. Another objective was to assess the retrofitting methodologies and evaluate their effectiveness in mitigating the damaging effects of ground shaking [32]. These three organizations also deployed two missions. The first mission was deployed following the 2016 Amatrice earthquake and the second mission after the earthquake sequence in 2017 when it was considered safe to enter the restricted zones [32]. The mission teams were formed by engineers with expertise in lifelines and structures focused on bridges and buildings. Besides engineering aspects, the mission collected data related to emergency management and the performance of critical infrastructures (CI) such as hospitals and schools [32]. 


\subsection{Omnidirectional imagery $(O D)$}

The outcomes of the fieldwork or ground surveys can be improved by the unique viewpoints and perspectives delivered by the OD camera technology. Employing OD cameras is possible to collect chains of omnidirectional images. The development of online platforms to host the collected images makes it possible that those photo chains can be easily visualized to simulate an immersive 'walk through' of a landscape with 360 degrees, ideal for comprehensive damage inspections in reduced access zones [34]. One example is the visualisation obtained with this technology is presented in Figure 5.

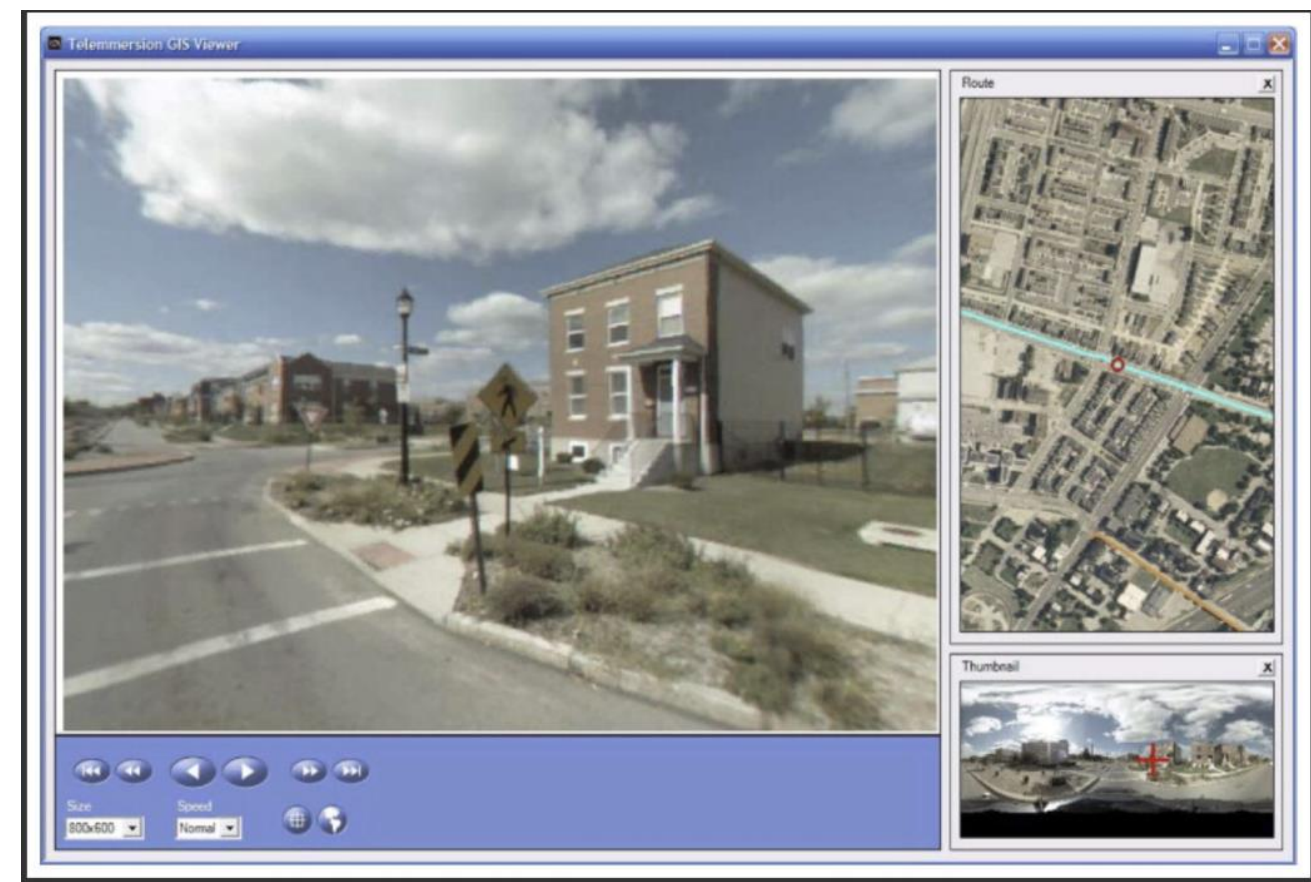

Figure 5. A portion of an OD image depicting a street intersection in St. Louis MO Source:[65]. Figure 1. Page.194.

Previous studies have reported an acceptable level of accuracy of virtual surveys compared to street ones [34, 66,67]. Chains of OD images could be utilized to increase sample sizes by improving statistical structural damage data, allowing robust sampling techniques to be used across an area impacted by an earthquake [34]. EEFIT tested this data source in two different post-earthquake contexts: the 2016 Muisne earthquake in Ecuador and 2016 Central Italy. In both cases, the same camera equipment was used: a Ricoh Theta S. The imagery was visualized employing the Mapillary platform to assess construction typologies, number of stories and degree of damage [34]. The context of the two EEFIT missions is different in the scale of the damage, the buildings affected, the urban context, the local topography, and the earthquake's characteristics.

In the 2016 Muisne earthquake in Ecuador, damage data collected through a series of rapid visual surveys (RVS) conducted in the field was compared to the data collected virtually along the same routes using chains of OD images. This mission validated the utilization of OD imagery with RVS data to compare virtual surveys later using OD imagery to the damage data extracted from satellite imagery [34]. In 2016 Central Italy, the work was focused on testing OD imagery's ability, collected during the walk-through, on better understanding damage regarding the damage maps provided by the European Copernicus Emergency Management Service. These maps were delineated based on the timely geospatial information derived from RS and completed with available open data sources in situ for emergency response [34]. 
This technology shows significant capabilities in identifying aggregated 'low' and 'high' damage grades, failure modes, number of stories and construction typologies. There are some potential issues with the proper identification of disaggregated lower damage (e.g.Damage grades 0-3 according to the European Macroseismic Scale-98) [34]. The comparison of RVS and OD based post-earthquake survey data identified challenges to overcome. Those challenges are poor image quality; insufficient photosphere captures related to the extent of its overlap, lack of photos close enough to each other, and obstructions such as trees, walls, or vehicles [34]. More advanced cameras could improve the image quality, and the gaps between pictures can be solved by reducing the distance between images (between 6 and $12 \mathrm{~m}$ ), especially on obstructed streets (e.g. tree-lined). Moreover, uncertainties related to the validity of the information inferred using this method and the challenges associated with collecting detailed data still need to be addressed.

\subsection{Terrestrial laser scanning (TLS)}

Detailed structural and geotechnical surveys can be done to obtain high-resolution digital elevation models (DEM) using TLS [8]. This method managed to capture the entire geometry of the Baptistery of San Giovanni in Florence, Italy, with the level of detail required to identify and measure cracks (see Figure 6), settlement, displacement, missing mosaic tiles and other types of damages [35]. This data collection method uses a scanner that reflects a laser off a rotating mirror to acquire a sphere of measurements from one central point of view. Terrestrial laser scanning uses a time of flight measurement technique that calculates distance based on the time it takes for the laser to return from a surface or a phase shift method that compares the emitted and received phases of the laser $[35,68]$. TLS provides accurate 3D geometry with millimetres [69] and range, reducing the effort involved in measuring and post-processing [70]. The laser scanner integrates a global positioning system (GPS) and correlates individual scans in post-processing, making it suitable for surveying based damage assessment. Another technique for detailed survey is Structure from Motion (SfM); this photogrammetric technique uses two-dimensional images taken from multiple viewpoints to compute a $3 \mathrm{D}$ representation of the scene being surveyed. Both TLS and SfM are line-of-sight (LOS) techniques, which means that the device only records measurements from the first surface it sees and nothing beyond that. In case of 3D environments, multiple imaging positions are therefore required to perform a complete digital 3D representation [35]. 


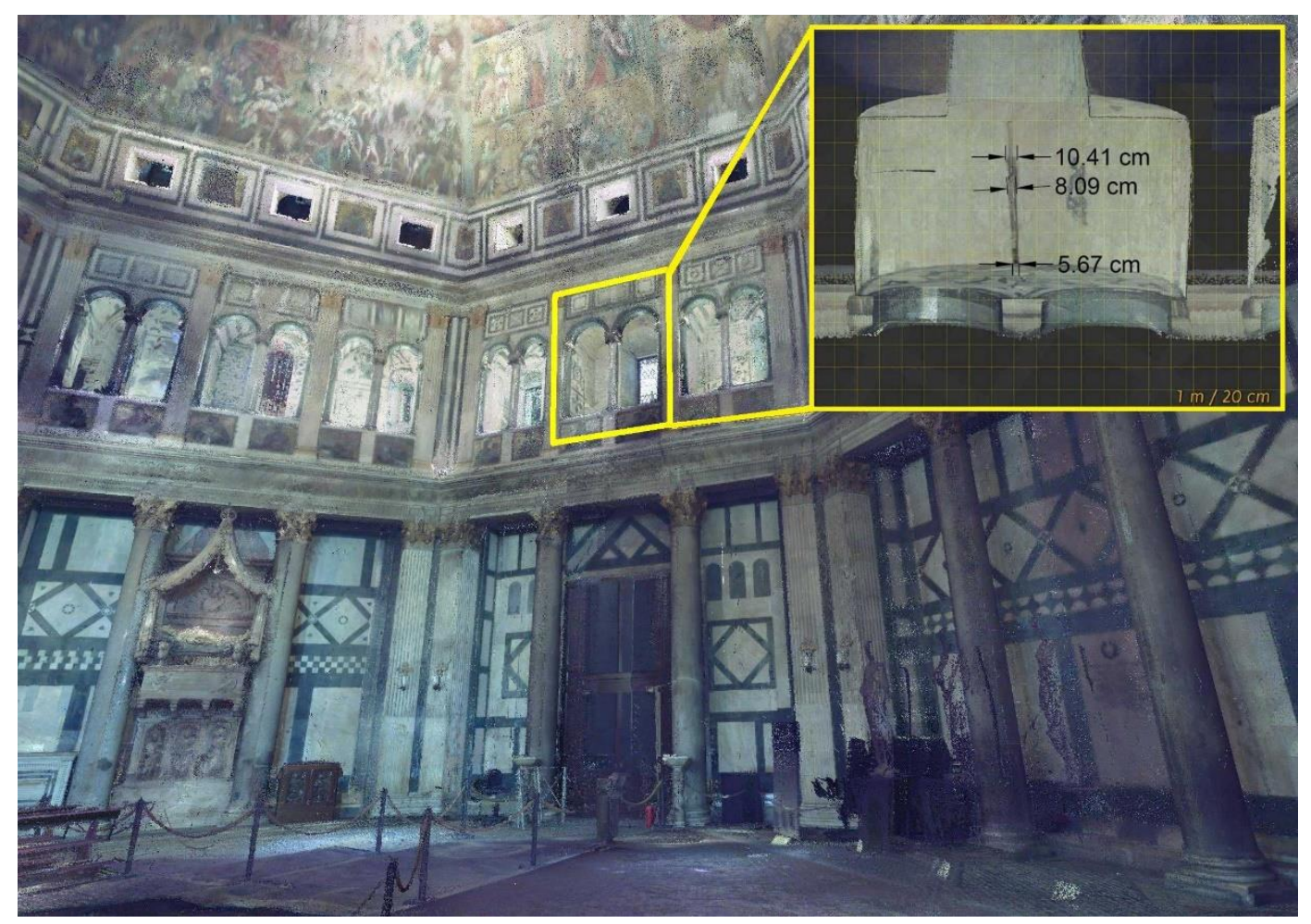

Figure 6. Scanning data highlighting the dimensions of a crack above the North door of the baptistery di San Giovanni in Florence. Source: [35] Figure 12, page 257.

\subsection{Remote sensing (RS)}

The building-by-building inspection may not be possible in areas with significantly damaged structures. Therefore, it is necessary to consider alternative contactless, non-invasive RS techniques and means to safely inspect and report the operative conditions and structural health of affected buildings [9] and do this over a wide area. Imaging technology has increased rapidly as data gathering tools boost mission capabilities and ensure safe deployment in areas affected by earthquakes [34]. For about the last decade, highresolution optical satellite and aerial images have been increasingly used for a rapid building-damage survey after an earthquake [24]; they have become an important tool for rapid and reliable structural damage assessment (SDA) [21]. We identified in our literature review six RS data sources used for earthquake reconnaissance. Those sources are satellite images, UAVs, sUAV, LiDAR, high-resolution synthetic aperture radar (SAR), InSAR. The RS data sources are organized below according to the complexity to extract and process the data collected.

\subsubsection{Satellite images}

Aerial photography was the source of damage data used to estimate the size of the impact area quickly, before the availability of very high resolution (VHR) satellite images. The spatial extent of building damage after earthquakes can be detected by combining pre and post-disaster very high-spatial-resolution (VHR) satellite images such as Quickbird [36]. Images are compared for change detection (CD) [37] using approaches such as Pixel or object-based image analysis (OBIA), visual or manual interpretation with the support of geographic information systems (GIS) software $[18,36]$. Damages in buildings are detected according to changes detected in relational (borders), spectral (ratio, mean, Gray Level Co-occurrence Matrix1 - GLCM texture, brightness) and spatial (compactness, volume, shape) features [36] A heat map based on the location changes in buildings between 
2009 and 2011, following the earthquake in L'Aquila is depicted in Figure 7. Very highresolution satellite images can also be used to reference historical data compared with VHR images acquired by UAVs for CD [37]. Satellite imagery accurately captures the higher damage levels, but it is coarser in capturing lower damage degrees due to technical limitations of the distance and the atmospheric conditions when an image is captured and the satellite optical radius, affecting levels of the output accuracy. Then, in building damage assessment, further data is required, given that the level of detail provided by satellite images is not satisfactory [34]. Satellite images are also valuable for generating accurate digital elevation models (DEM)[71], which are later used to detect and monitor ground and structural deformations [36].

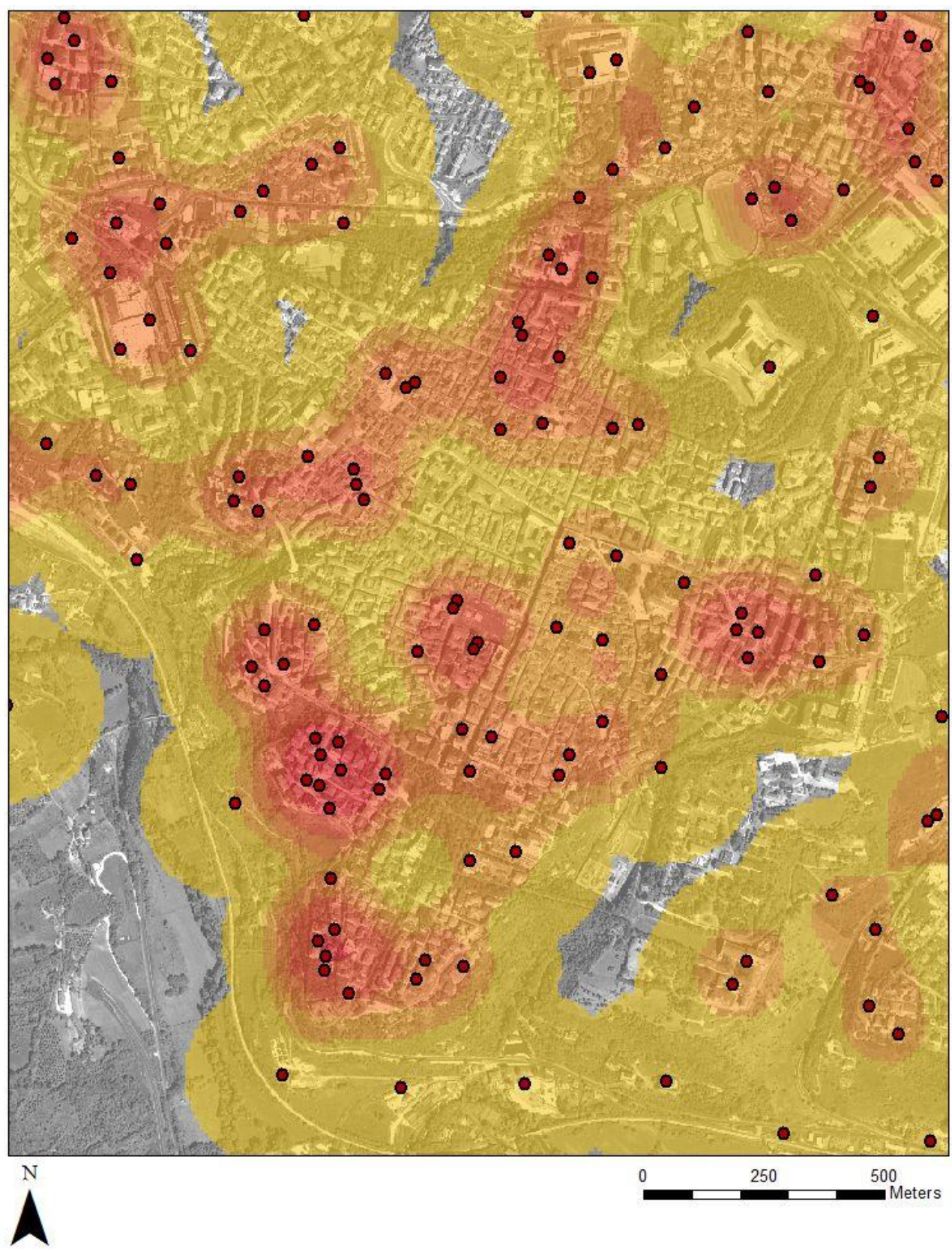

Figure 7. Location of changes in buildings between 2009 and 2011, following the earthquake in L'Aquila (heat map). Source: Based on QuickBird/DigitalGlobe, European Space Imaging on 11 September 2011 [36]. Figure 6, page 11.

3.4.2. Unmanned aerial vehicles (UAVs) and small Unmanned aerial vehicles (sUAV) 
After earthquakes, overflights with aeroplanes and helicopters are initially done to identify the extent of the affected area. However, a new source of post-disaster aerial data has matured with UAVs $[8,21]$. This method can be effectively used to acquire images of a target region quickly. It is even more effective when the UAV images are sent immediately for processing to an operational ground control station. The spectral information is a crucial aspect of the change detection problem under study, depending on the sensor loaded on the UAV platform and less on the reference image that can be selected later to be compared to the images produced by the UAV sensor [37]. UAVs capture multi-perspective high-resolution imagery, are easy to transport, deploy and fly, accesses easily destroyed areas and are cost-effective than traditional airborne approaches [37, 38]. The GEER mission for the Central Italy case selected UAVs as one of the principal data collection tools to take images for assessing potential landslides based on their portability, rapidity in data collection and superior field of view [31].

The GEER team utilised three UAV platforms. Two commercial off-the-shelf (COTS) UAV platforms and one customized/modified for aerial photography: DJI Phantom 4, Sensefly eBee, and Align TRex 800e, respectively [31]. The first UAV p Post-event dual polarimetric SAR images for earthquake damage assessment latform was employed to collect high-resolution imagery from a sloped or vertical surface, where vertical control was required. The second UAV platform was utilized to capture nadir images of places over large areas, given their superior speed and flight endurance. The third platform was employed in only one location, considering constant heavy winds in that specific place. The onboard camera of the UAV is the governing factor that determines the quality of the data collected. Speed and altitude can be adjusted mid-flight, while minimal adjustments can be made for improving camera performance. Digital single-lens reflex (DSLR) or DSLR-equivalent cameras are chosen over point-and-shoot cameras, but they require larger UAV platforms to carry them [31].

Automated sUAV (0.6 kg of platform weight) acquired images of damages in the mountain village of Pescara del Tronto after the earthquake in 2016. Later automated sUAV were also used to collect images of the progress of the reconstruction efforts in 2018 [63]. The imagery data was used for 3D reconstruction using SfM. The sequential 3D reconstructed models enable building identification, movement detection, volumetric measurements and document recovery progress [63]. The 3D models were developed using Bentley ${ }^{\mathrm{TM}}$ ContextCapture. This software establishes the 3D point locations in a scene using camera metadata and GPS. The photos contain the data utilized to calculate inter-spatial intersections [63]. A view-planning algorithm delineated optimized angles and photo locations through 'greedy heuristics' to capture better orthogonal views of Pescara del Tronto and solve the drawbacks of the nadir grid approach. This view-planning algorithm identifies the best sensor location for observing a site or an object by planning oblique images for optimized SfM [63]. These computational tools together produce photogrammetric outcomes that look down vertically and at several oblique angles. In 2018, two new algorithms were applied to capture the images during the return mission: optimized view and flight path, which increased the completeness of the 3D models by providing additional oblique angles, which allowed the generation of textured mesh models and dense point clouds. Automated sUAV enabled data collection on the city's reconstruction, geotechnical background and the surrounding countryside [63]. The advantages of utilising sUAV in earthquake reconnaissance are that it makes it unnecessary for the missions to enter damaged areas and therefore reduces the inspection time for data collection [47]. They collect physical, social and economic data by looking at the number of urban facilities reopened after an earthquake and counting the number of pedestrians and vehicles in streets at specific hours and days in the week. One of the constraints to obtain data through this source is the increasing regulation for the operation of UAVs and the rapidity that these regulations are evolving. Nevertheless, UAV's valuable role for impact estimation after 
natural phenomena is acknowledged by most regulatory agencies, favouring the acquisition of the flight permit [31].

\subsubsection{Light Detection and Ranging (LiDAR)}

The LiDAR approach has been used to estimate the damage after earthquakes [72] and hurricanes [8] along with other disasters. One approach consists of laser-generated point cloud data containing 3-dimensional (3D) coordinate information and reflection intensity of a building, which are integrated into an algorithm used for the structural assessment using photogrammetric techniques [72]. Another approach consists of a densitybased algorithm to extract building clusters. Then, a cluster-matching algorithm is developed to match post-event and pre-event building clusters using multi-temporal datasets. Roof features involving changes in the area, volume, orientation and shape are identified as indicators of building damage [73]. High-rise or median-rise buildings are relatively easy to detect in airborne point cloud data as they have large footprints compared to residential homes [73]. Although LiDAR is significantly slower than UAV-based inspections, it was still faster than manual inspection of large areas and its accuracy higher than UAVbased remote sensing [31].

Detailed structural surveys can be done using terrestrial light detection, and LiDAR and the GEER team used it at landslide locations during the reconnaissance mission in central Italy [31]. Light Detection and Ranging can cover large areas and be highly accurate, but shadows cast by changes in hillsides and slopes can block critical areas of view. In this case, additional surveys from alternative directions are necessary for fusing with a UAV-based SfM point cloud model [31].

\subsubsection{High-resolution synthetic aperture radar (SAR)}

This technique is a sort of radar used to generate two-dimensional images or threedimensional reconstructions of landscapes. To generate a SAR image, successive pulses of radio waves are sent to 'illuminate' a target, and the echo of each pulse is received and recorded. The pulses are transmitted, and the echoes are received using a single beamforming antenna, which location changes as the SAR device on board the spacecraft or aircraft moves [74]. Synthetic aperture radar is essential for obtaining disaster information given its strong penetrability through tree canopies, speediness, comprehensive coverage, and all-time/all-weather imaging capabilities. It is often used to detect not only building damage but also to monitor ground and structural deformations [49]. In 2010, after the earthquake in Haiti, heavily damaged urban areas were assessed using SAR intensity images and building footprints [10]. Pre- and post-event high-resolution SAR images and their characteristics are depicted in Figure 8. The backscattering coefficient between preand post-earthquake images changes more in collapsed buildings than in less damaged ones because the rubble has a stronger reflection. This analysis has managed to detect almost $75 \%$ of the damaged buildings correctly [12]. 

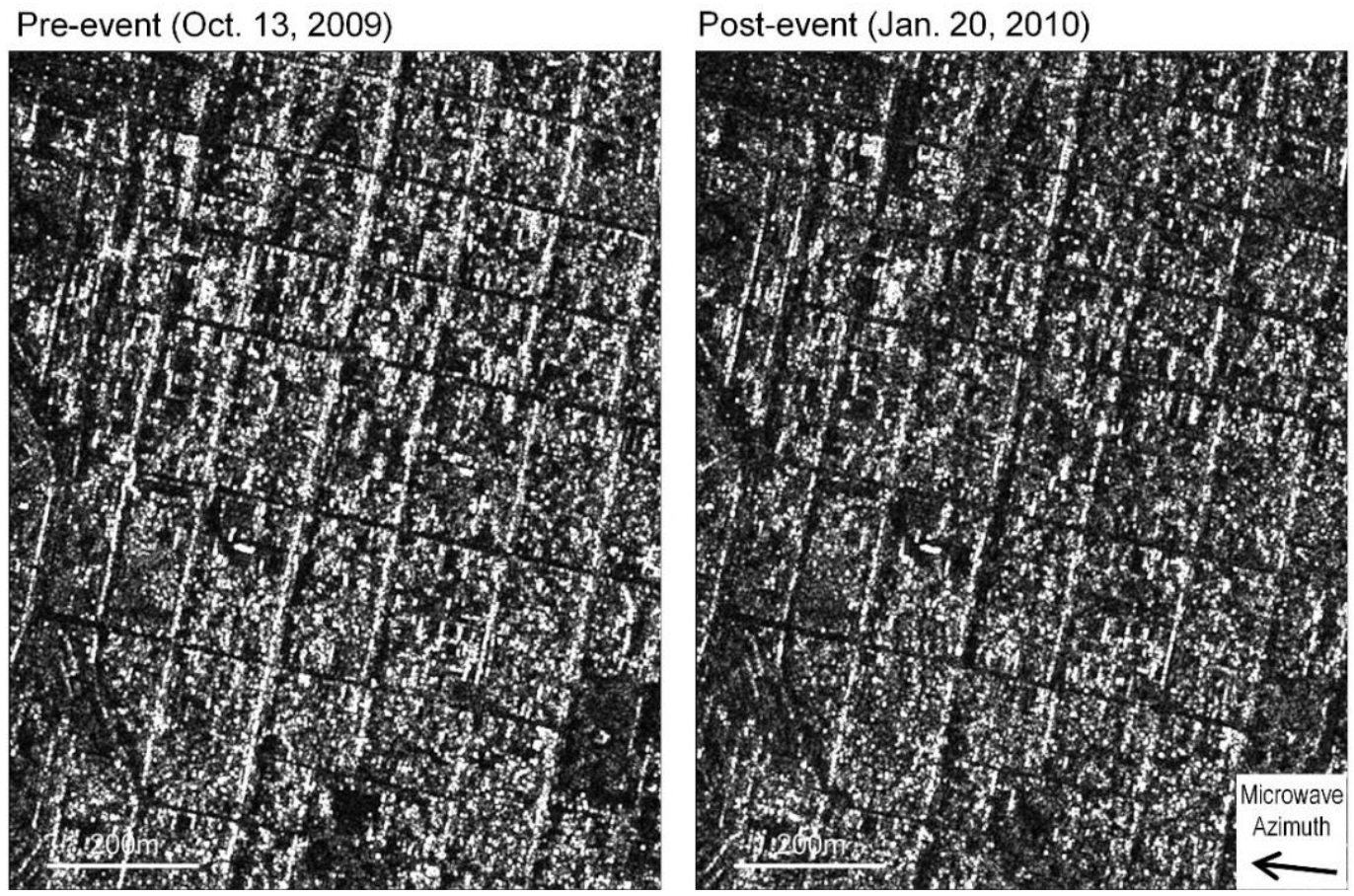

Figure 8. Pre- and post-event TerraSAR-X (TSX) images in target area observed in descending Orbit. Source: [10]. Figure 3, page 595.

Post-event dual polarimetric SAR images for earthquake damage assessment were used for the 2015 Nepal earthquake. Polarimetry refers to the vector nature of electromagnetic waves. Radar polarimetry is the science of acquiring, processing and analysing the polarization state of an electromagnetic wave in radar applications [75].

In radar physics, the backscattering coefficient signifies the backscattering ability of them scattered on the ground to the received radar electromagnetic wave. According to polarization, there are three typical scattering types: surface, double-bounce and volume. Undamaged buildings present a high backscattering coefficient given the double-bounce scattering, whereas damaged presents a low one. The radar scattering characteristics of undamaged and damaged urban areas are compared using polarimetric features derived from PALSAR-2 and Sentinel 1 images [39]. Supervised classification, feature selection and split-based image analysis were utilized on the images [39]. Pearson's correlation coefficient is adopted as a criterion to select high correlation features utilized to construct classifiers. The outcome of this process indicated that texture features derived from the backscattering coefficient were the most appropriate to identify the building damage. Higher correlations were found between the damaged and texture features derived from the intensity cross-polarization than other features considered [39]. Support vector machine (SVM) and K-Nearest Neighbor ((KNN) classifiers were applied for supervised classification. Employing 30\% data for testing and 70\% of the data for training, the support vector machine (SVM) classifier reached an accuracy of $80.5 \%$. Earthquake damage Visualization (EDV) use SAR data for rapid detection of earthquake damage considering three parameters. The first parameter is the normalized difference between pre-seismic and coseismic coherences, and vice versa, to calculate the forward (from pre-seismic to co-seismic) and backward (from co-seismic to pre-seismic) change parameters, correspondingly [15]. The second parameter is the backward change added to visualize the changes not caused by the earthquake. The third parameter is the average values of the pre-seismic and co-seismic coherence maps. These three parameters were eventually merged into the EDV as a red, green and blue (RGB) composite imagery [15]. The earthquake damage is visualized efficiently through the EDV employing Horizontal transmit and Horizontal receive $(\mathrm{HH})$, and Horizontal transmit and Vertical receive (HV) polarizations data from the Advanced Land Observing Satellite-2 (ALOS-2) [15]. The performance of the EDV was tested in the Kathmandu Valley, struck by the 2015 Nepal earthquake [76]. The cross-validation 
results indicated that the EDV is more sensitive to building damage than other methods and its utilization in other earthquakes is feasible [15]. In the last years, SAR based techniques have been also applied to recognize earthquake-related surface deformation and ruptures, massive landslides and subsidence [71]. High-resolution synthetic aperture radar data from Sentinel-1 and near-field GPS data from four stations was utilised to investigate the coseismic and postseismic surface displacement associated with the Gorkha earthquake [41]. The deformation map generated revealed an upliftment of about $1 \mathrm{~m}$ near Khatmandu and a subsidence of about $0.8 \mathrm{~m}$ toward the north [41].

\subsubsection{Interferometric Synthetic-Aperture Radar (InSAR)}

This technique uses SAR images of the same area obtained at different times [77] to map ground deformation [78]. Comparing InSAR coherence maps from and after an extreme event can produce damage proxy maps (DPM) [31, 79]. Radar and optical images were combined to measure ground displacements and determine the kinematics and geometry of thrust faulting for the Himalayas after the Mw 7.8 Gorkha, Nepal [40, 42, 43]. The InSAR data from the European Space Agency(ESA) was processed to derive surface offsets and surface LOS ground motion from the correlation of amplitude images from Landsat- 8 and SAR [80]. These observations were complemented with other published surface displacements from ALOS-2 SAR satellite and GPS coseismic offsets. Up to 2 metres of south-southwest motion and almost 1 metre of uplift in Kathmandu basin and the surrounding Lesser Himalaya were observed, whereas north of this, a large region of the higher Himalaya subsided by about 0.6 metres [80]. Nevertheless, a triggered near-surface slip was found with the Sentinel-1 coseismic interferograms along 26- km-long discontinuity, $10 \mathrm{~km}$ north of the MFT. Broadly consistent surface offsets, peaking 60 millimetres of surface motion towards the radar, were showed by independent interferograms on two overlapping descending tracks [80].

Interferometric Synthetic-Aperture Radar and GPS were utilised to study coseismic and early postseismic deformation associated with the Gorkha earthquake by mapping done by different groups of researchers [41]. The analysis of data collected found coseismic and early postseismic (4-88 days) surface displacement. The same geodetic data was inverted for coseismic and postseismic slip on the Main Himalaya Thrust (MHT), providing a detailed slip distribution pattern on the causative fault. The postseismic GPS displacement supports the InSAR observations and the inverted coseismic deformation closely matches the observed InSAR and GPS deformations. The InSAR data pair (29/04/2015-11/05/2015), along with the GPS-derived velocity for a window time of 13 days, was chosen for afterslip inversion as it represents early postseismic movements (416 days after the Gorkha earthquake) [41].

\subsubsection{Real Aperture Radar (RAR)}

The RAR technology can be used for rapid building condition screening to provide almost real-time, trustworthy information about its condition and performance. The radar device can detect and range objects by acquiring echoes from different targets contained in its antenna field of view (FOV). This RAR and other pieces can be observed in Figure 9a). A radar observation utilises the time elapsed between the transmission and reception of an electromagnetic waveform to provide a signal called range profile. This signal consists of peaks of different amplitudes that identifies the observed structure's main reflecting parts [6]. When a good signal-to-noise ratio (SNR) is obtained, an interferometric algorithm can be used to look at the changes in the phase of the reflected signal so that the time-shift can be extracted, and hence the vibration within the damaged building can be estimated.

Numerical modelling and RAR were used to record the displacement response of a selected building severely damaged due to the Mw5.1 2011 Lorca earthquake (Spain), as it 
is portrayed in Figure 9b). The IBIS-S, a radar device with interferometric capability, a sensor module, a control PC, a power supply and data procession software were employed to monitor the displacement time history of the vibration of the surveyed building [6]. The objective of this test was to determine the feasibility of the RAR-based method to identify the safe state of a damaged building after an earthquake, avoiding accessing unsafe structures [6]. The result shows a good consistency between the experimental and numerical approaches and the observed damage, demonstrating that RAR is a supplementary RS method to safely report a building's operative conditions and structural health after an earthquake [6].

a)
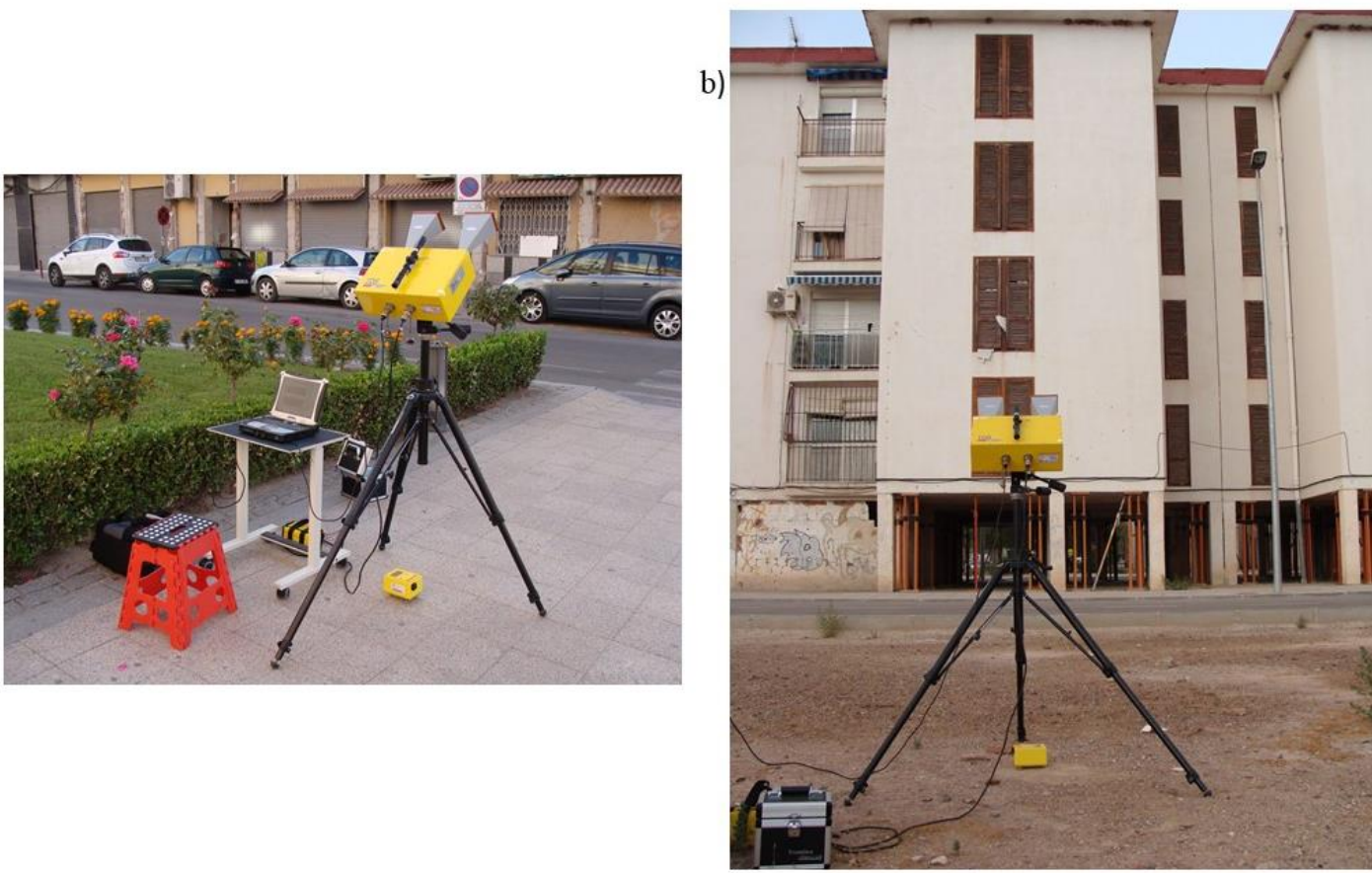

Figure 9. RAR. a) RAR device and b) RAR device and building. Photos: Dr. Ramón Gonzalez-Drigo. Source: [6]. Figure 2, page 18.

\subsection{Crowdsourcing platforms}

Eyewitness reports have always been part of seismology, and large volumes of eyewitnesses observations can boost rapid situational awareness [46]. Online tools offer the possibility that 'citizen engineers' and volunteers to analyse large amounts of data to quickly provide a qualitative assessment of damage degree and different types of buildings post-earthquake [34]. We identified in our literature review seven crowdsourcing platforms used for earthquake reconnaissance: DYFI, Earthquake network, LastQuake, MyShake, Raspberry Shake, QuickDeform and The TSERSystem. The crowdsourcing platforms identified are listed below in alphabetical order.

\subsubsection{Did You Feel It (DYFI)}

The United States Geological Survey (USGS) developed DYFI in 1999. 'Did You Feel It' is an online system to collect macroseismic intensity (MI) data, shaking and damage reports from earthquakes eyewitnesses to process them automatically [46] for generating intensity maps right after an earthquake [44]. This system distributed questionnaires after earthquakes to collect information about their impacts [50]. In the case of earthquakes outside the United States, DYFI data rapidly confirm their occurrence for seismic analysis, and scientists at the USGS National Earthquake Information Centre (NEIC) can use this to indicate the impact of shaking effects quickly. Intensity data collected through DYFI are 
utilized to provide shaking constraints input for the USGS Global ShakeMap system. This information allows the USGS to alert agencies and users worldwide of significant earthquakes and their likely impact [44].

Incoming entries from multiple web servers are processed and aggregated over postal ZIP codes (in the US), and 1-km and $10 \mathrm{~km}$ aggregated boxes for each earthquake to make interactive maps and plots served via the USGS Earthquake Program web pages [44]. The DYFI is a program for community internet intensity maps (CIIM) developed based on the questionnaires filled in that assigns average intensity level to each ZIP code [54]. Two relevant questionnaire indices are combined with other users within their community to produce an intensity calculation [44]. Did You Feel It contributors usually select the most recent earthquake when contributing or searching for information [44, 46]. Some of them still contribute for months after an earthquake; therefore, DYFI maps result from aggregated MI models that change over time. The DYFI questionnaire includes questions about user's situation, experiences, and behaviours, going beyond the calculation of MI. This data makes the DYFI database, the repository of millions of comments relevant for social sciences [44]. Essentially, DYFI depends on entries from the general public, being citizenbased science. Shakemap and DYFI have significantly facilitated the use of MI in the US, training citizens to think in terms of varying intensities produced by an earthquake [44].

\subsubsection{Earthquake network}

Earthquake Network is a citizen science research project implementing an earthquake early warning system (EEW) based on smartphone crowdsourcing [51]. People install this smartphone application and receive real-time alerts when the smartphone network detects earthquakes [45]. The Earthquake Network app is, at the same time, the instrument to detect earthquakes. When the smartphone is unused and charging, the app monitors the accelerometer for detecting vibrations likely due to an earthquake. If a seismic movement is detected, a signal is sent to a server that collects signals from smartphones $[45,51]$. Following the algorithm, the server decides in real-time if an earthquake is happening. If confirmed, the server infrastructure sends an EEW to the users located in the affected area. Hence, the Earthquake network makes an early warning service available to users interested in making their smartphones available for detection when their smartphone is not in use [45]. The Earthquake Network app interface is depicted in Figure 10.

For real-time detection of earthquakes, the Earthquake network sends signals to a server located in Europe. The infrastructure is currently based on nine servers that receive a large number of signals from the network and the numerous users opening the app when they experience the earthquake. Whatever signal received by the server infrastructure activates a statistical algorithm that determines if an earthquake is happening. Then the analysis is done at a global scale and in real-time [45]. Users can report the impact of an earthquake pushing a button in the app interface, reporting the earthquake's impact considering only three levels: mild, strong, and very strong, to make it fast. Spatial coordinates of the smartphones are automatically sent with the felt report. If several reports are received from a specific area simultaneously, a notification is sent to the smartphone users through the Firebase Cloud Messaging (FCM) platform. Usually, users receive first the EEW activated by smartphones, and within one minute, they receive the notification activated by users. The user is redirected to a map showing all felt reports by clicking on the notifications. As an example, reports were collected in Puerto Rico within 60 seconds after the 3.6 Magnitude earthquake; thus, users were aware of the low impact of the earthquake before any official information was released [45]. Earthquake Network app has a second strategy to send smartphone coordinates by SMS or email to a list of trusted contacts when an EEW is received. The aim is that SMS/e-mail will be sent before lifelines 
(phone network/Internet) are affected and the EEW received before the shaking starts. However, the smartphone must be on at the time of the earthquake. After receiving the SMS/e-mail, users can report their status by pressing a button in the app's user interface indicating: 'I am fine' or 'I need help'[45].
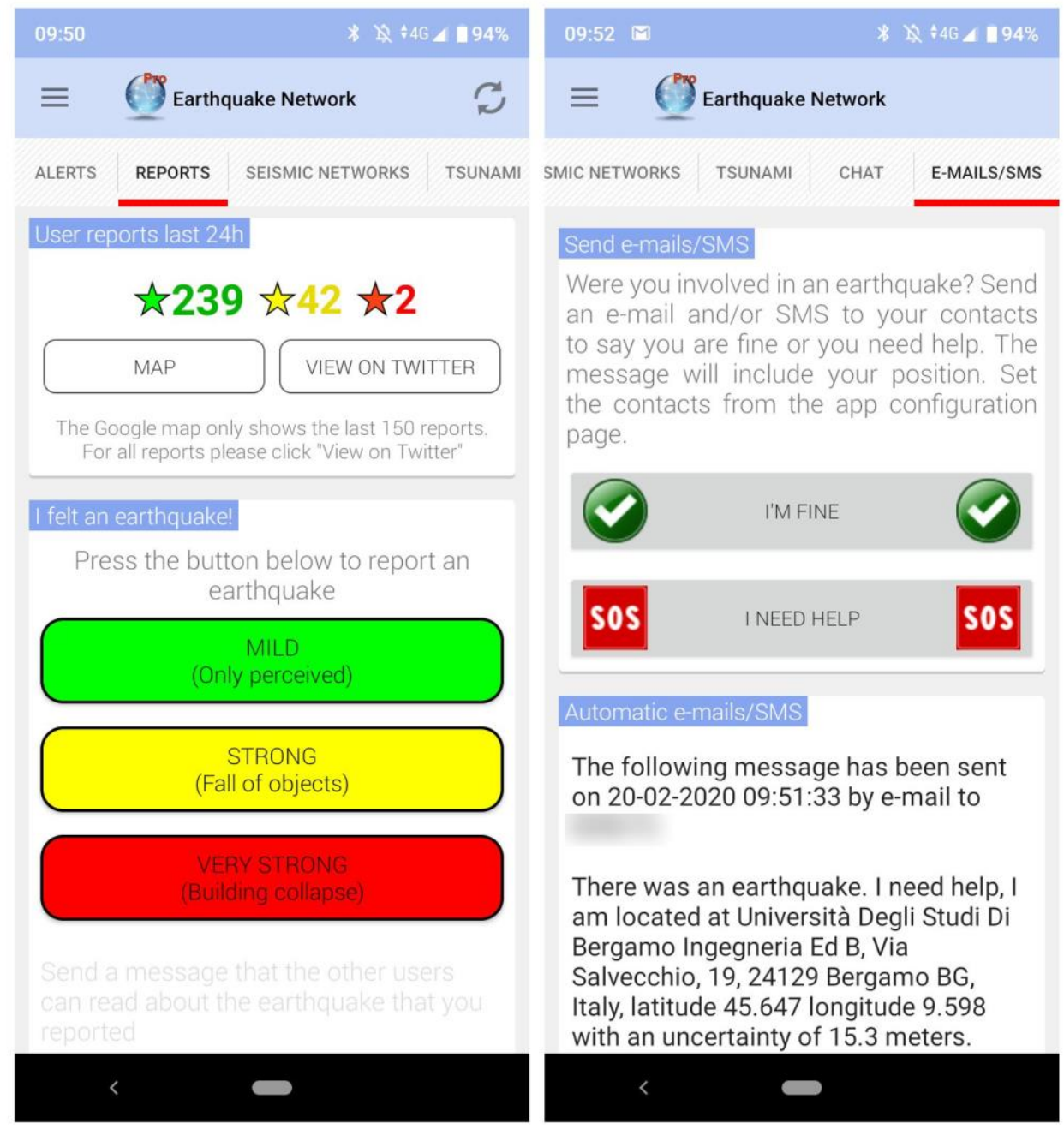

Figure 10. User interface of the Earthquake Network app for sending felt reports (Left) and for asking help if involved in an earthquake (Right). Source: [45] Figure 3, page 5.

\subsubsection{LastQuake app}

The European Mediterranean Seismological Centre (EMSC) developed a multichannel rapid information system consisting of websites, a Twitter quakebot called LastQuake, and an eponym smartphone app [44-46, 51] at the interface between global users looking for information the EMSC. Components of this multichannel rapid information system are presented in Figure 11. This multichannel has two objectives: To offer practical information in regions where an earthquake is felt and to collect reports from users containing direct and indirect observation related to the intensity and damages caused by the earthquake [16]. LastQuake app also monitors people activity soon after the earthquake [45]. LastQuake app users' engagement is built on the rapid provision of tremor detection. Users' behaviour is similar to real-time seismic sensors when they enter the EMSC websites or the smartphone app. An earthquake can generate several automatic tweets published by the quakebot and updates on the website. These tweets and updates describe earthquake parameters, epicentral plot, maps, felt reports, historical seismicity, tsunami information and links to the user's comments [16]. 


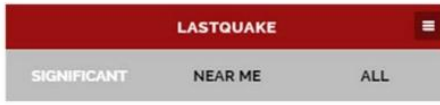
N Earthquake possibly felt 2 min ago:
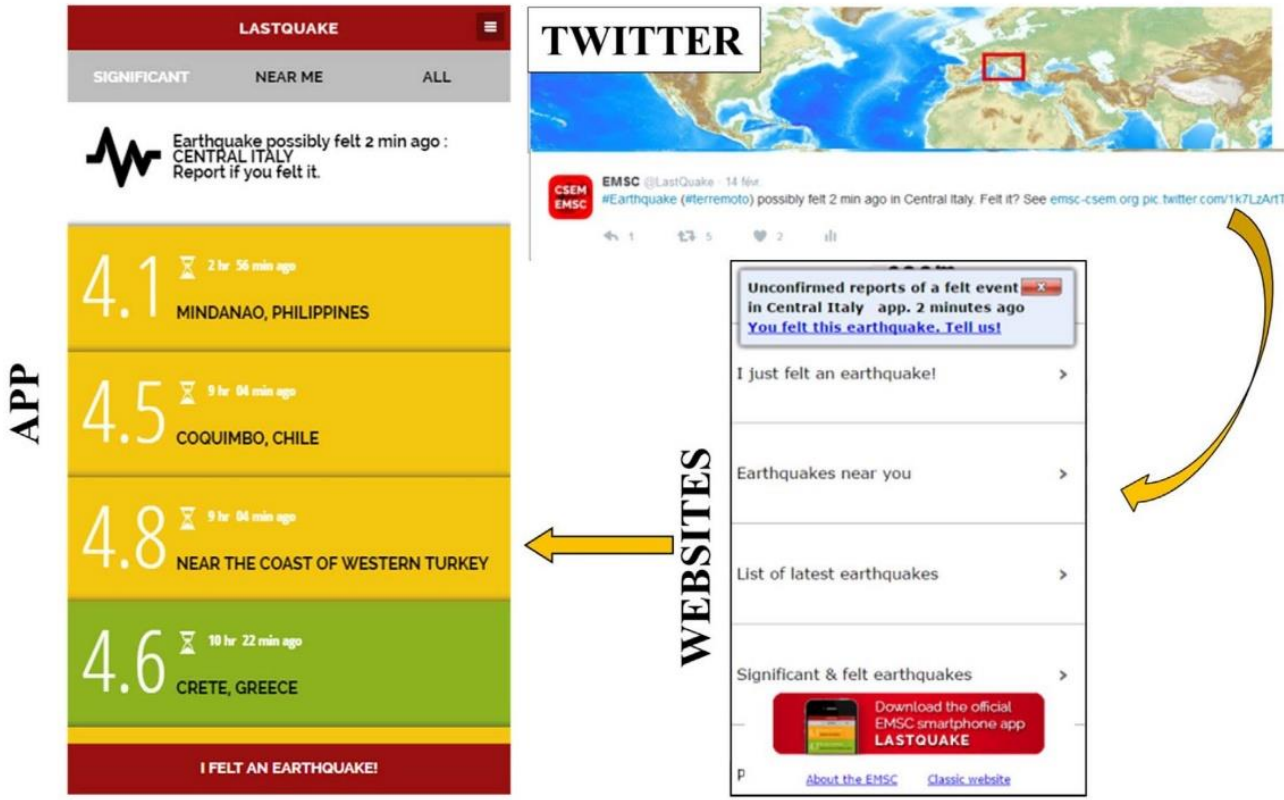

CSESC
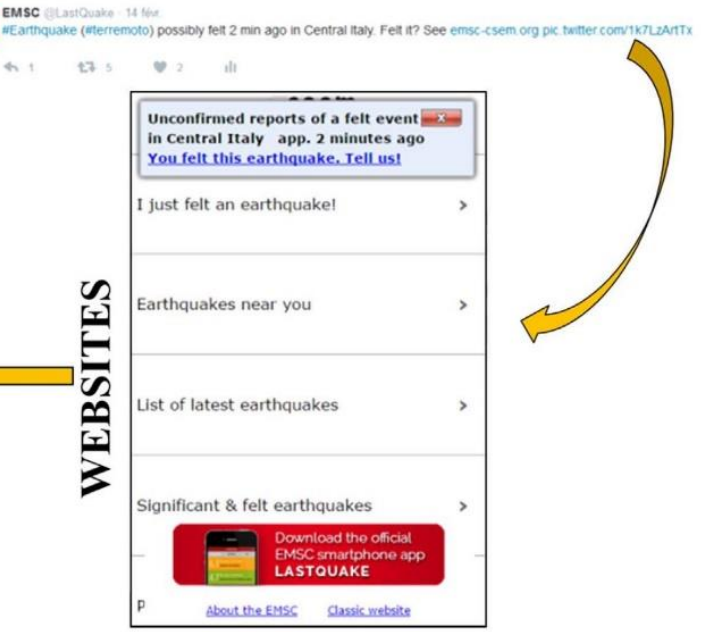

Figure 11. Components of EMSC's multichannel rapid information system. Source:[16] Figure 3 , page 35 .

There are two kinds of data collected from users: crowdsourced data (felt reports, geotagged pictures, videos and open comments) and crowdsourced detections (users reactions and experience on the ground) [16, 46]. Then it is only necessary to identify the geographic origin of the website visitors through their Internet Protocol (IP) to determine where the earthquake was felt without the need for any seismological data [16]. There are two other complementary crowdsourced earthquake detection methods in operation: Twitter Earthquake Detection (TED). This approach identifies a surge in tweets, including the keyword 'earthquake' in various languages and the traffic analysis generated by LasQuake app launches, which works like the website traffic analysis. If many people in the same area open the app simultaneously, there is a high probability of an earthquake, and hence an alert is sent [45]. A push notification is submitted to LastQuake app users once the crowdsourced detection has been confirmed. Felt reports are collected through a multilingual online macroseismic questionnaire available on the EMS website or using the 12 cartoons depicting different shaking and damage levels [50]. Each cartoon represents an intensity level of the European Macroseismic Scale 1988 [46]. These cartoons have made more efficient the collection of reports at a global scale [16]. Plotting the location of the LastQuake app launches is possible to map the felt area automatically.

\subsubsection{MyShake project}

The 'Myshake' project aims to build a global smartphone seismic network to develop a large-scale EEW and other applications to boost the power of crowdsourcing [45, 47]. This project implemented by UC Berkeley Seismological Laboratory [45] is based on MyShake mobile application, which first detects earthquake shaking on a single phone. Then this detection is confirmed on the MyShake servers using a 'network detection' algorithm activated by multiple single-phone detections [47]. This app is utilised to continuously monitor the smartphone accelerometer to measure earthquakes and send alerts [45]. It is assumed that $0.1 \%$ of the population in each region has the MyShake mobile application installed on their smartphone. The system works better (alerts generated between 4 and 6 seconds, errors are within to 0:5 magnitude units, and epicentres are typically within 10 $\mathrm{km}$ of true locations) in high-density populations and onshore regions with an upper crustal earthquake with a magnitude higher than M7:0. In the opposite case, in low-density 
populated regions and in offshore areas, alerts are slower, and the uncertainty in magnitude and location soar. The system still works where only $0.01 \%$ of the population use the MyShake app, in highly populated regions and earthquakes with a magnitude higher than M 5.5 [47].

\subsubsection{Raspberry Shake}

Raspberry Shake is a crowdsourcing operation based on affordable seismic sensors that can be easily installed in houses or schools and used in several citizen seismology projects [51]. After the 2015 magnitude 7.8 Ghorka earthquake in Nepal, it was found that the population was not aware of their country's high seismic hazard. Hence, an initiative to introduce seismology in schools, focusing on education and citizen seismology, was implemented in Nepal [48]. Considering its performance in a laboratory test, suitability for the field conditions, the seismic sensor installed in schools was a Raspberry Shake 1D (RS1D). Additional criteria to select this sensor were low cost (below 500 USD), easily applicable for educational purposes, high sensitivity to detect local earthquakes, ease to handle and the possibility of recording data without an additional computer. These seismometers installed in 22 schools develop the Nepal School Seismology Network delivering online data openly [48]. This program started in Western Nepal because people there have limited opportunities to learn about earthquakes. There has been no significant earthquake for 500 years in this region $[48,81,82]$, and there is an acceptable travel time by vehicle or short walk between different sites where seismometers were installed. Facebook and Twitter were used in Nepal to spread information about the Nepal School Seismology Network and ask interested schools to fill in the request form [48]. The criteria to select the 22 schools among 100 that submitted the request form were: number of students, motivation, feasibility to instal the seismometer on the ground floor, $200 \mathrm{~m}$ as minimum distance to road or highway to avoid anthropogenic noise, own internet connection, alternate power supply and reachability of the school [48]. Each seismometer installed in a school inform students about earthquakes, waveforms, distance and magnitude of the event. Thus, the network is used for both sharing locally recorded data openly and teaching [48].

\subsubsection{QuickDeform}

Near real-time ground deformation maps generated after earthquakes are essential for hazard assessment and usually take a couple of hours or longer to be generated by conventional means. A near-real-time coseismic ground deformation map generation system to assist emergency response is developed by Zhao, Liu and Xu [49]. This system adopts source parameters published by the USGS-NEIC and empirical equations to generate the real-time (within seconds) coseismic ground deformation maps [49]. This method integrates seismic deformation maps into WebGIS for real-time disaster evaluation and emergency response. The seismic ground deformation maps are integrated as self-adapting spatial data fusion using the Okada rectangular dislocation model [83] and empirical equations of fault [49]. Later the result is visualised on an interactive WebGIS platform named: QuickDeform. This GIS user-oriented platform provides real-time evaluation and emergency response information by viewing, searching, and customizing the seismic deformation [49].

\subsubsection{The Taiwan Scientific Earthquake Reporting (TSER) System}

The TSER is a crowdsourcing system designed for acquiring quantitative data collected by trained volunteers for earthquake-triggered surface damages [50]. This TSER is an experimental program launched by the Institute of Earth Sciences, Academia Sinica, and Taiwan's Seismological centre in 2016. These institutions incorporated in the program: (1) computer-aided volunteer management system (VMS), (2) educational training course and (3) online report and mapping platform [50]. Additionally, volunteers were trained 
to ensure the quantity, completeness, quality and reliability of the data collected when they report the damages produced by earthquakes. The TSER was developed in the framework of a citizen seismology program that includes training courses and VMS with the web GIS-based platform to crowdsource scientific users reports for earthquake-triggered surface natural damages [50]. The on-site field reports complement the ground observations from the field with real-time instrumental data and results to better understand the surface damages and geohazards produced by earthquakes and support SAR activities and later social impacts [50]. The TSER system was constructed adopting the pre-existing Ushahidi mapping platform, which was widely used successfully for several purposes [50]. Ushahidi platform is an open-source software application and an integrated data crowdsourcing and mapping tool that allows people to collect, manage and analyse data from their communities [84]. The VMS notifies a trained volunteer of a potentially damaging earthquake through email. These notifications indicated the epicentral area to carry out field surveys. Volunteers must log into the TSER platform. To report earthquake-induced surface damages, they must identify the ground damage category from a menu, describe it, locate it, and upload the corresponding picture [50]. The collected information is made available to the public after being checked by the on-duty scientist. The TSER platform was tested after the $2018 \mathrm{Mw}$ 6.4 Hualien earthquake providing the distribution of the surface ruptures, rupture orientation, type of faulting and offset dimension [50].

\subsection{Social media (SM)}

Social platforms and smartphone apps are playing an increasing role during disasters[85]. They offer not only public participation but also constitute backchannel communication. Considering that the internet and SM have become the digital nervous system of our planet [16], various forms of SM are valuable tools for quickly collecting large amounts of data relating to disasters. It offers first-hand data, observations, sentiments, and perspectives [86]. This data can range from photos, videos, and comments uploaded to various internet platforms and Facebook, Twitter, Instagram and Youtube.

The first fieldwork or ground survey that reported have extracted data from SM was the mission deployed by Stanford's John A. Blume Earthquake Engineering Centre for the 2017 Puebla-Morelos earthquake. This mission complemented the collapsed buildings' database with data from newspapers and SM [27]. Nowadays, SM platforms have become another medium to share early scientific analysis, forming collaboration bases among multidisciplinary teams. We identified in our literature review three SM platforms used for earthquake reconnaissance: Earthquake Network, Facebook and Twitter. The SM platforms identified are organized below in alphabetical order.

\subsubsection{Earthquake Network}

Probably the first social network about earthquakes was Earthquake Network. This platform has chatrooms in 10 languages, where users can share information right after an earthquake, either in private messages or in the public space. Chat moderators in the public space keep the discussion focused on relevant issues and block users that misbehave [45]. Earthquake Network supports people after they have experienced an earthquake by enabling discussions with others to reduce the anxiety and fear caused by it. Those users active in the chatrooms tend to keep the app installed for months to years [45].

\subsubsection{Facebook}

Facebook is the most popular SM platform [51, 52] for user-generated content. Lastquake app users have the option to share their comments on their Facebook account [16]. In May 2018, the French Island of Mayotte in the Indian Ocean between Madagascar and the coast of Mozambique was struck by a series of earthquakes. At the beginning of the seismic swarm, there was a gap in seismic data and explanations of the phenomenon and a 
mistrust of the scientific community. Residents using the LastQuake app [16], created their citizen seismology network based on a Facebook group named: Mayotte Earthquake Support (STTM by its acronym in French) [51]. The members of this group on Facebook expressed their scepticism about the lack of information from the seismologist community. After the first earthquake, they started to discuss its effects on the road traffic group. Following this, one group administrator decided to create a group dedicated to earthquakes [51]. Citizens created this group for citizens to exchange knowledge and feelings about earthquakes. Generally, after an earthquake, citizens post messages indicating when and where they felt it and, in some cases, ask for additional information such as magnitude. They also show and ask for emotional support, commenting on each others' posts and questions, uploading pictures of cracks or trees on the roads, and discussing the earthquakes' potential causes [51]. Over time, this group took a more scientific direction, and some of the members shared reliable seismic information in an understandable way for their fellow citizens. The information shared was about seismology in general, seismological concepts (magnitude and intensity) felt earthquakes, earthquake causes, comparisons with other earthquakes swarms, historical seismic data and safety measures to take [51]. These citizens collected data, reviewed scientific literature, and produced collated forms of knowledge, listing all felt earthquakes mentioned in the group and comparing them to the French Geological Survey (BRGM's by its acronym in French) seismic reports. Furthermore, a few months after the earthquakes, one of the users suggested equipping the island with a Raspberry shake seismometer $[48,51]$.

\subsubsection{Twitter}

The Palu Mw 7.5 earthquake and tsunami in Indonesia and other events have demonstrated how Twitter quickly generates knowledge in the minutes to hours and days following an event developing an efficient exchange of information and active discussion between the public and scientists and between scientists themselves [52]. In the aftermath of an earthquake, it is essential to promptly establish its geological and geophysical characteristics to be able to explain it to the media and stakeholders and evaluate the risk of secondary effects [52]. In Hurricane Sandy, the Twitter activity was correlated with damage and, therefore, useful for impact assessment and response [16, 87]. Correlation between the number of tweets and the intensity of an earthquake was observed for the first time in 2010. During the Tohoku earthquake, researchers observed a high correlation between the number of tweets and the earthquake's intensity in some locations [88, 89]. Informative tweets about geophysical data were made for the 2018 Palu - Sulawesi island, Indonesia. Based on these tweets, a timeline was built of the rapid progress of understanding the earthquake rupture and its effects. Published papers, maps about the seismotectonic context in Indonesia, teleseismic data, local seismic waveforms, high-resolution optical satellite images, SAR, tide gauge records, and field observations from both science groups and local residents were shared on Twiter, getting rapid and varied feedback from fellow researchers [52]. The correlation between activity on Twitter and Mercalli intensity was demonstrated in Napa, California [54], Japan, and Chile [53]. The activity on Twitter related to recent earthquakes is plotted in Figure 12. 
a)

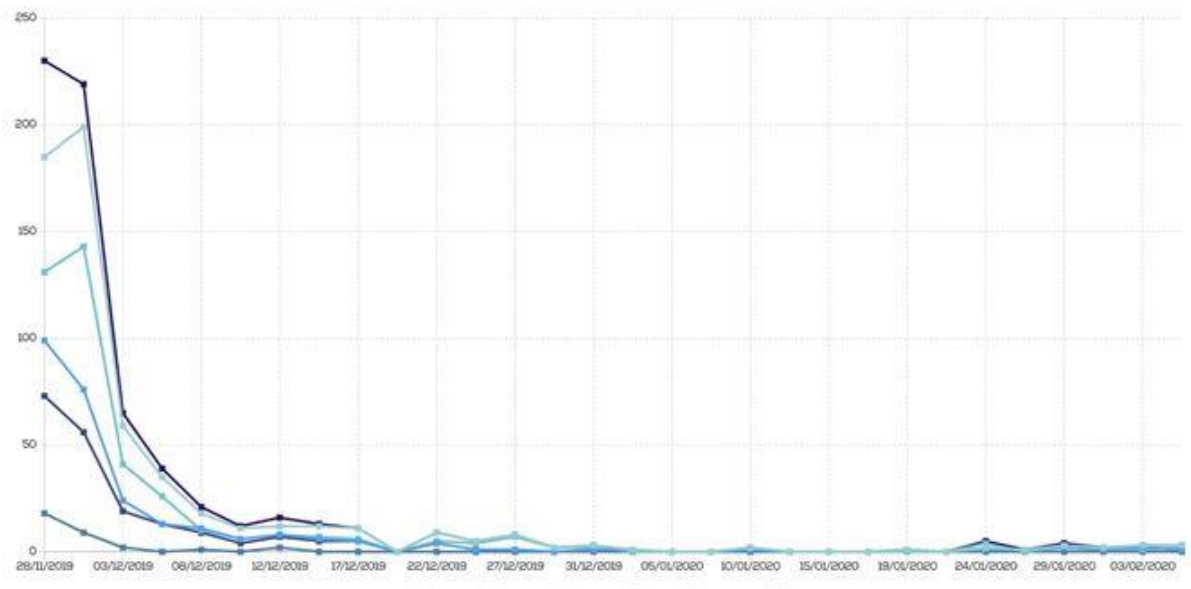

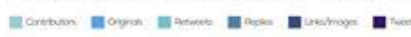

b)
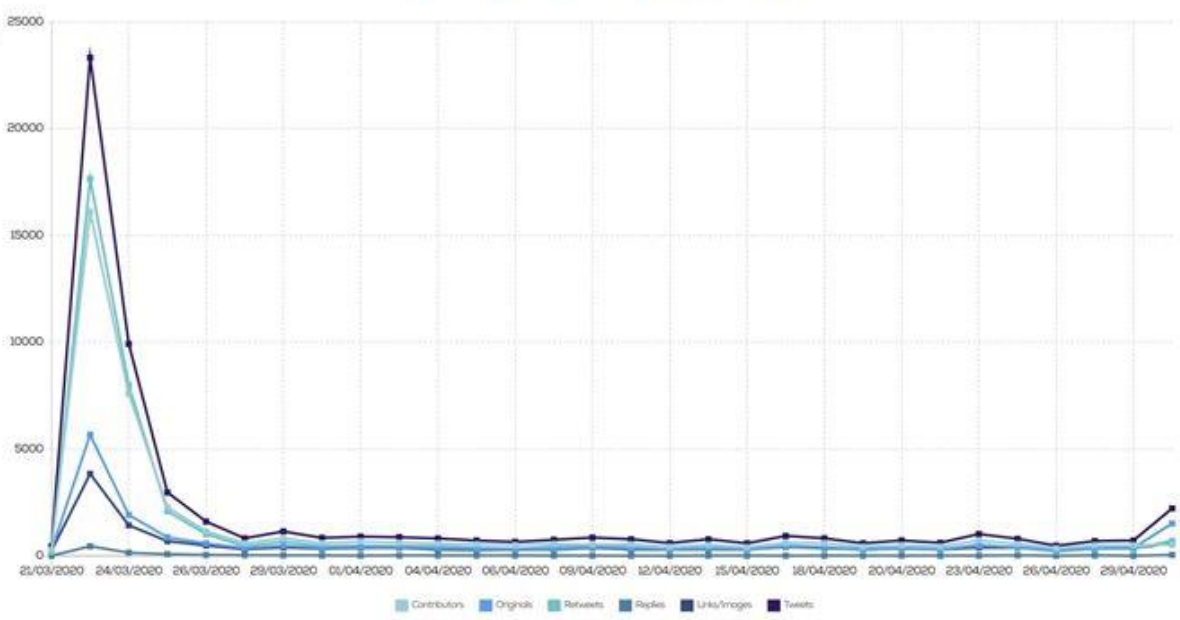

c)

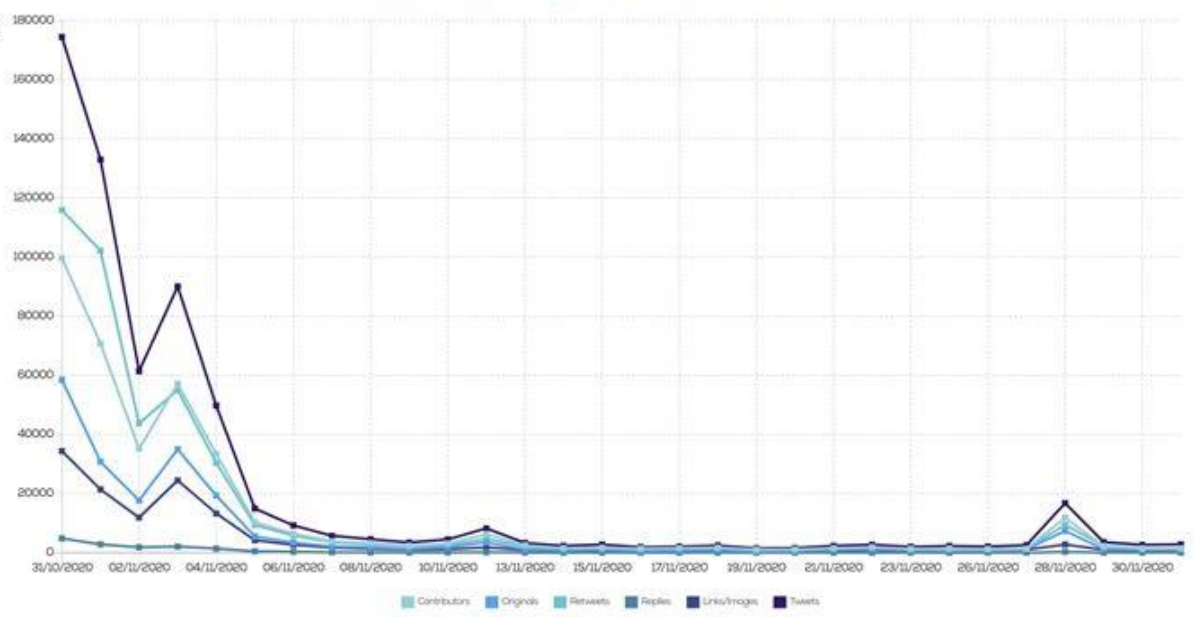

Figure 12. Twitter activity related to a) 2019 Albania earthquake; b) 2020 Zagreb earthquake; c) 2020 Aegean earthquake. Source: TweetBinder.

\subsection{Closed Circuit Television Videos (CCTV)}

This source of data continuously records images at a given location. By definition, the video record should be temporally comprehensive (ignoring recording failures), although, in some instances, recording may start when a change in the image is detected. Either way, CCTV videos can provide good quality data about how the image at a given location change depending on the camera's resolution. As the camera is static, it is 
relatively easier to use automated techniques to detect changes in the background image and potentially automatically relate that to an earthquake impact. One of the issues with using CCTV images for CD due to an earthquake is that the cameras are generally privately owned. Therefore, discovering useful images or gaining permission to view those images is not assured.

The Collection of 38 amateur videos and CCTV's at 14 sites around Palu Bay were used $[52,55]$ to estimate tsunami arrival times, amplitude and wave periods around different locations, where more damage was reported after the MW 7.5. 2018 Palu earthquake. The Pantoloan tide gauge data was complemented with an innovative approach that combines the analysis of video footage and post-tsunami surveys. The video images captured the formation, propagation and inundation of the tsunami. Timed waveforms were constructed from the quantitative interpretation of video footage $[90,91]$ by tracking sea levels changes from image pixels in subsequent frames. The quality and the quantity of the videos determined the richness of the tsunami data. While several CCTV cameras precisely capture tsunami scenes, others were captured by amateur videos. This analysis provides temporal data that is not possible to recover in field surveys. The video footage combined with post-tsunami surveys indicated evidence of potential locations of submarine landslides as tsunami sources that would correspond with the arrival times of the waves [55].

An image-based disaster damage assessment system named IDEAS has been developed to evaluate damage assessment inside buildings. This system first compares images taken inside a building before and after an earthquake. Later these images are used to map the damage according to a Mercalli intensity scale [56]. To perform the earthquake intensity scale assessment, IDEAS adopts scale-invariant feature transformation (SIFT) to extract the information of non-structural objects moved. Afterwards, IDEA uses the information and the size variants of non-structural objects that have moved for damage assessment of the buildings [56]. To extract the movement information of each object, IDEAS performs multiple object tracking to assess the damage and map it according to the MMI scale. Later, IDEAS submits the damage assessment report to the relevant audience, such as institutions in charge of emergency response. The working scenario of IDEAS is depicted in Figure 13. To determine the accuracy of IDEAS, 40 pairs of CCTV images from the Youtube website were collected. The test reports an accuracy of $97.6 \%$ in mapping the Mercalli intensity scale [56].

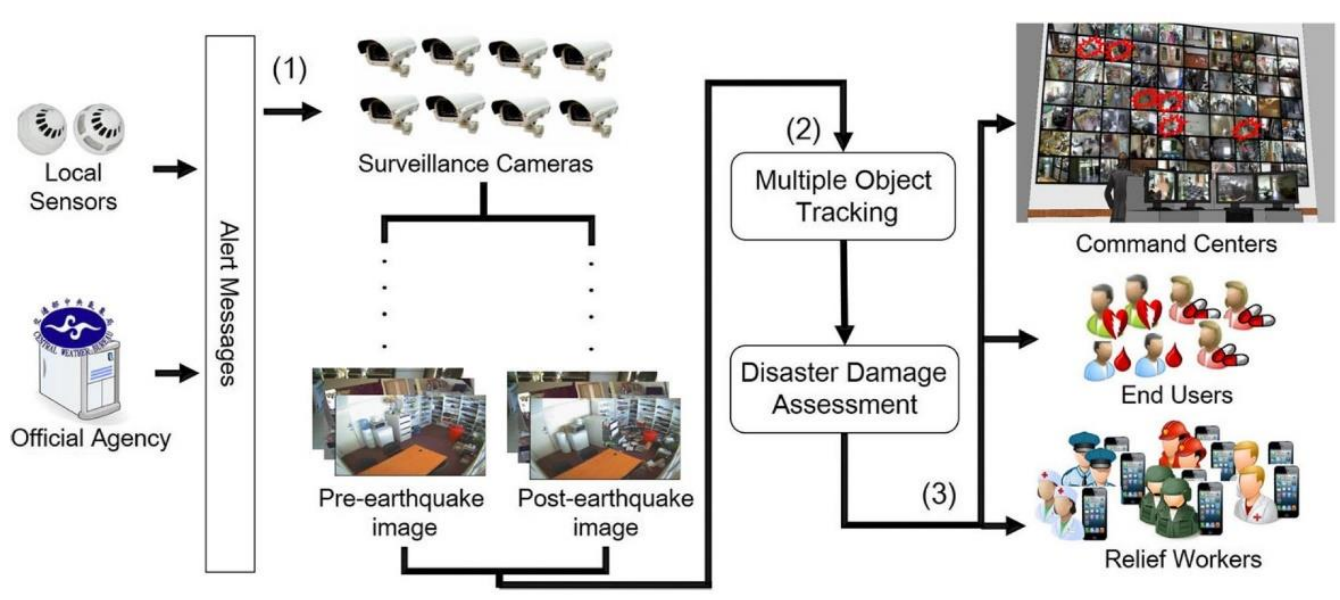

Figure 13. A use scenario of IDEAS. Source: [56] Figure 1, page 1725.

\section{Discussion}


In 2019, this review was planned as a systematic review; however, only using the keywords: 'damage' AND 'earthquakes' excluded important references about innovative data sources, methods and tools for collecting building damage data employed in other natural phenomena such as hurricanes. The outcome of the search using these two keywords was 34 references, which were reviewed. In 2021, we revisited the data sources, methods, and tools identified in the first literature review to focus only on those references relevant to earthquake reconnaissance and/or addressed during the LfE UK project. Then we used the keywords 'earthquake reconnaissance' and each of the data sources identified in the first literature review. In both literature reviews, the references were identified from Web of Science because we consider it the most comprehensive curated database available. Social media platforms tend to be the new data sources, and given the travel restrictions imposed by the COVID-19 pandemic, we also used them for this paper. We did not focus the review on them because there was already a literature review on this topic [83]. Furthermore, we identified data sources that include other methods and tools that collect data at more detailed scales and complement the data collected through SM. While we considered and included the references published in 2014 and 2015 identified in the first literature review, we did not count them because we aim to highlight state-of-the-art (last five years).

Building-by-building foot-on-ground surveys collect highly detailed data that can be used forensically to validate RS data or models such as structural models or fragility curves [92]. However, they are expensive and time-consuming [60], and the duration of these inspections can last for months [52] depending on the availability of volunteers [93] to reach a good understanding of the event's characteristics [52]. Nevertheless, it is necessary to differentiate between a rapid building damage survey [94], which is focused on buildings safety during the emergency phase and a detailed damage survey oriented to assessing the performance of building structures or the restoration of historic buildings [35]. This second kind of damage survey can support early recovery planning and help to accomplish build back better and built to last. Now, smartphones allow quicker and more rigorous structural evaluations by filling in forms in apps that contain all the necessary items to evaluate the damage of a building and collecting multimedia data. The collected photos can be indexed by their locations using the GPS coordinates [95] or what3words. Eventually, post-earthquake investigation data can be quickly uploaded to servers through the network of smartphones so that seismic damage data can be quickly shared to support decision making for post-disaster recovery [33]. The use of TLS to capture the entire geometry of the Baptistery of San Giovanni in Florence, Italy, was not used in the context of an earthquake reconnaissance mission. However, we decided to include this reference for the suitability of this method in reconnaissance missions when they need to focus on the forensic analysis of world heritage (WH) buildings.

The main advantage of using RS for building damage assessment is that large damaged areas could be surveyed rapidly without being hampered by the emergency operation on the ground [24]. Smaller and particularly complex urban disaster scenes, multiperspective aerial imagery obtained with UAVs and sUAV and derived dense colour 3-D models are becoming increasingly employed to gather data. Hence, it would be interesting to investigate if the regulation for the operation of sUAV is less strict because its use supports the rate and delineation of areas struck by earthquakes and the resulting models provided a detailed reference source for the tracking of recovery efforts during return missions. These data sources are an alternative to identify damage not based on CD in satellite images and remove challenges such as the images do not match each other [37]. Currently, satellites are equipped with several RS payloads to complement airborne remote sensing and other UAVs. The result is a collaborative operated network involving multiple satellite observations, airborne RS, and ground operations [18]. 
The ubiquity of smartphones and SM have opened new opportunities for fast crowdsourcing and two-way communication between affected people and institutions/authorities [46]. In some cases, one geotagged picture, an individual observation or comment, on SM platforms can substantially reduce uncertainties regarding impacts [46]. However, the scientific community still cast doubts on the utility and reliability of data collected in the framework of citizen science projects. To ensure the quality of data collected through the crowdsourcing TERS system, the Institute of Earth Sciences, Academia Sinica in Taiwan, trained volunteer users among high school or junior high school teachers in natural sciences in geology, historical earthquakes and associated surface damages, geohazards, TERS and volunteer reporting system, citizen seismology and field geology excursion with on-site practices [50].

Crowdsourcing information can be a cost-effective option to form a dense real-time accelerometric network, reducing uncertainties of rapid earthquake scenarios [46]. Although the intrinsic variability felt reports, based on 20 years of DYFI experience [44], it is possible to observe how felt reports have contributed to earthquake response and science and behaviour studies [44,46]. Integrating DYFI data in ShakeMaps improves shaking estimates and the rapid assessment of earthquake's impact [44, 46]. Earthquake Network app and MyShake app are similar. The main difference between these apps is that the data recorded by the accelerometer in the Earthquake Network app is not used to make any seismological analysis and EEWs are sent only when several smartphones in the same area detect accelerations above a specified threshold [45]. Currently, the main limitations of the EEW system implemented by the Earthquake Network are the lack of accuracy in the information of the earthquake intensity and that the geometry of the location of the smartphone network is not optimized regarding known faults [45]. Among these apps, the EMSC was the first to consider the behaviour of users and their associated digital footprints to detect a widely-felt earthquake in an intersection between seismology, citizen science and digital communication. This approach was also compared with the manually and independently derived macroseismic datasets from DYFI [46]. However, when looking at intensity levels reported by users, it is necessary to keep in mind that those living in low seismic zones tend to report a strong earthquake, regardless of the magnitude and/or impact displayed in the app user interface [45]. Another common problem among citizen science projects is user retention, which could be solved by encouraging interaction with the app and other users to boost user lifetime value [45]. In the case of Mayotte, it was observed that while scientists were gathering on Twitter [52], citizens were debating on Facebook about the same seismic phenomenon. The answers to the questions formulated on the STTM group were available on Twitter. This situation can be explained by the socio-technical design of the platforms and the technological culture. People use Facebook for daily and personal uses. Instead, Twitter has become a handy platform for researchers to exchange ideas, collaborate and share preliminary outcomes [51].

Earthquake reconnaissance missions can also take advantage of images uploaded on SM platforms such as Instagram and Flickr. However, we did not find any literature reference that mentioned the use of Instagram, a fact that could be explained based on our experience because pictures published on Instagram are accessed through Twitter. Flickr, this platform is an American image and video hosting, which has been used in military defence [96], to monitor and evaluate post-disaster tourism recovery after typhoon Haiyan [97] and to prioritize the collection of RS imagery as a filtering tool after the Colorado floods [98]. However, Flickr has not been used yet in earthquake reconnaissance and could also be another suitable data source. We accept that neither crowdsourcing platforms nor SM constitutes groundbreaking science. Instead, the process of automating the extraction of meaningful information from the text and image data they provide to support earthquake reconnaissance missions could be the future direction of research.

\section{Conclusions}


This literature review was beneficial not only to go through each of the most used data sources in the last five years but also to recall the most significant seismic events in the same period. Considering an initial literature review undertaken in 2019 plus the experience gained in the project: LfE-UK: We conclude that the current data collection sources can be grouped into seven categories: fieldwork or ground surveys, OD, TLS, RS, crowdsourcing platforms, SM and CCTV.

We know that data sources based on fieldwork missions and RS have been used for decades; however, they are still evolving in terms of their capabilities and their use. Nowadays, fieldwork missions use apps to record the building damage assessments instead of paper forms and increasingly include RS methods with more functionalities and devices with higher resolutions, precision and accuracy. Something similar happens with crowdsourcing platforms, DYFI has existed since 1999 [44]; the Earthquake network started in 2012 [45]; the LastQuake app existed before 2015 [16]; Raspberry shake [99] and TSER system [50] were launched in 2016; MyShake network detection algorithm was tested in 2018 [47] and the first reference about Quickdeform dates from 2020 [49]. Although Facebook and Twitter were launched in 2004 and 2006, these SM platforms have evolved in response to the feedback from their users and their ability to generate income for the owners. For this reason, and their expanding use in providing data from disasters, we argue that they can be considered to be part of state of the art.

The most detailed and reliable data is collected through fieldwork or ground surveys that last between three days to one week on-site [28]. There must be at least a previous week to collect information of the affected area, searching for local contacts and logistic preparation (team members selection, flight tickets purchasing, hotel booking, equipment preparation, visas and so forth). After the mission, it is necessary to process the data to produce a final report. The partnerships between visiting earthquake reconnaissance teams (who have reconnaissance experience) and local institutions (who have local knowledge) are essential for efficient and effective data collection and interpretation. The fieldwork or ground surveys usually rely on traditional methods for data collection. However, the earthquake reconnaissance missions in the period covered by this literature review started to incorporate new technologies and sources, e.g. the app customized in the framework of the LfE- UK project tested by EEFIT mission for the 2019 Albania earthquake; the omnidirectional imagery for the 2016 Muisne earthquake and Central Italy, the data extracted from SM by the Stanford's John A. Blume Earthquake Engineering Centre for the 2017 Puebla-Morelos earthquake and the ambient vibration recordings done by the ATC mission for the same event. Smartphones have already replaced paper forms, overcoming issues such as the battery's duration of charge and technical compatibilities are still issues to solve. Omnidirectional imagery represents a significant improvement in damage assessment accuracy over satellite imagery, especially for lower damage grades [34]. Terrestrial laser scanning is the data collection method suitable for historic structures affected by earthquakes that need a precise restoration to keep their WH condition and precisely estimate the cost and time needed for their reparation or reconstruction [100].

The RS data sources are satellite images, UAVs, sUAV, LiDAR, SAR, InSAR, and interact between them. Satellite images are suitable for CD to identify damages in buildings and infrastructure, while SAR and InSAR techniques are more suitable for CD in landsurface altitude. The Building Safety Evaluation (BSE) teams conducted the field survey on behalf of Christchurch City Council in the weeks following the Feb 22, 2011, earthquake to validate findings from RS images [24]. The GEER fieldwork mission on Central Italy integrated data from several sources satellite-based interferometric DPM, published reports about landslides in the case study area, digital imagery from UAV, manual observations and TLS. Good agreement was found between the UAV images and the zones of the significant ground surface changed detected by DPMs [31]. Observations on steep 
terrain relied on UAV and LiDAR to collect data. The combined use of UAV and targeted terrestrial imagery allowed to build a large dataset of images with the outcome of various two-dimensional (2-D) and 3-D scaled representations of the observed landslides [31]. Terrestrial LiDAR point cloud models demonstrated to be handy intermediaries between manual inspections and UAV [31]. There is no unique RS method to obtain the accuracy and coverage expected in a post-earthquake reconnaissance mission, and so a number of different technologies should be considered. It is recommended to start with coarse RS methods such as optical image correlation and satellite-based interferometry to detect surface deformations and deploy more accurate RS data sources such as UAV-based SfM and/or terrestrial LiDAR to specific points of interest [31]. The inclusion of ground control points (GCP) and checkpoints (CPs) in the UAV-based reconnaissance landslide sites increases the accuracy of the resulting products [26] significantly. The Geotechnical Extreme Events Reconnaissance Association believes that data collection should rely in the future more upon UAV-based SfM and terrestrial LiDAR RS methods than in traditional manual observations. At the same time, they conclude that to increase the efficiency of a data collection task, earthquake reconnaissance missions must incorporate a phased reconnaissance approach where traditional measurements are only performed on valuable and essential places [26].

The crowdsourcing platforms used for earthquake reconnaissance are DYFI, Earthquake network, LastQuake, MyShake, Raspberry Shake, QuickDeform and TSER System. Crowdsourced detections are an efficient filter to identify earthquakes that attract public attention [16]. Social media platforms used for earthquake reconnaissance are Earthquake Network, Facebook and Twitter. Crowdsourcing and SM interact between them, complementing each other. Social media is a complementary data source of damage in buildings and lifelines, post-disaster needs, emergency response, and post-disaster recovery and situation awareness in general. However, it is still necessary to train citizens to provide more helpful information. The main aim of using SM is to extract information from image and text data to support data-driven decisions in earthquake reconnaissance. Crowdsourcing and SM are efficient sources of interdisciplinary data collection considering that they are within reach of everyone and interact between them, allowing users to share information, attract new users, boost new users, and boost new users and boost information and dissemination. Crowdsources such as the LastQuake system has evolved, elaborating on the earliest crowdsource experience, such as DYFI. Additionally, crowdsourcing and SM collects relevant data regarding damages description as interpreted by users, emergency response actions, and their fears related to their vulnerable condition. Currently, the information contained in this data has not been sufficiently explored. It is necessary to encourage citizens to keep on their smartphones apps such as Earthquake network, LastQuake app and My Shake. In this way, it is possible to ensure earthquake detection, receive EEW and collect first-hand data about building damages, tsunami and geotechnical effects, emergency response actions taken, and level of preparedness among users. To the best of our knowledge, the less explored data source is CCTV. This data source has been demonstrated to be useful in tsunami-prone areas such as Chile, Japan and the south Asian coast. Closed Circuit Television Videos can record the collapse pattern in buildings. In the future, the data collected can be used to monitor socio-economic recovery, counting pedestrian traffic during the early recovery, recovery and development phase [7]; however, protocols for obtaining relevant CCTV images need to be developed.

We conclude that the criteria to select a data source for earthquake reconnaissance include the time after the event (usually the post-disaster phase to carry out inspection); the size and topography of the area to survey; the time window to collect data, the estimated degree of damage; the type of assets damaged (e.g. structural vs. non-estructural elements) and the specific character of the inspection area. It is necessary to collect data in different scales for different levels of detail according to the assets damaged, each postdisaster phase's needs, and to consider several data sources, to have comprehensive 
information of the event. Currently, no reconnaissance mission can rely on a single source of data. It is necessary to combine different sources to complement and validate the data collected [36], especially in large survey areas, to quantify the damage comprehensively.

Data regarding physical damage and reconstruction can be collected through field surveys, OD, and TLS, which inspection area or points can be previously delimited according to data collected through RS, crowdsourcing, SM platforms and CCTV. The socioeconomic, institutional and cultural impact can be derived from SM platforms and CCTV right after the event during the relief or emergency phase and the early recovery, recovery and development phase. The increase in the number of Crowdsourcing and SM platforms as a source of data clearly indicates the tendency of data sources in the future. Currently, data do not exclusively come from scientists and/or authorities but also citizens. These citizens as sensors [101] are the group to be trained to obtain from them meaningful data to understand the characteristics of the earthquake and their impact on the social, economic, institutional, cultural and environmental dimension avoiding gaps in knowledge and information that give space to rumours and fake news.

\begin{abstract}
Author Contributions: For research articles with several authors, a short paragraph specifying their individual contributions must be provided. The following statements should be used 'Conceptualization, D.C. S.W. and P.J.; methodology, D.C.; investigation, D.C.; data curation, D.C.; writingoriginal draft preparation, D.C.; writing - review and editing, S.W.; visualisation, D.C.; supervision, S.W.; project administration, S.W. and P.J.; funding acquisition, D.C.,S.W. and P.J'. All authors have read and agreed to the published version of the manuscript.
\end{abstract}

Funding: Please add: This research was funded by the Engineering and Physical Sciences Research Council (EPSRC) [Grant No.: EP/P025641/1].

Data Availability Statement: Not applicable.

Acknowledgments: We would like to thank Professor Jeffrey Wilson, Dr Michael Hess, Professor Hiroyuki Miura, Dr Ramón González-Drigo, Dr Francesco Finazzi and Dr Rémy Bossu for providing us with pictures to illustrate the OD, TLS, RAR, SAR, Earthquake Network and LastQuake app data sources and granted us permission to include them in this paper. We thank our project partners: Dr Claire Ellul, Dr Valentina Putrino and Ms Enrica Verrucci for their input in the initial stage of this literature review. We appreciate the contribution from the anonymous reviewers with their observations, suggestions and questions.

Conflicts of Interest: Authors declare no conflict of interest.

\title{
References
}

1. Zook, M., et al., Volunteered Geographic information and Crowdsourcing Disaster Relief: A Case Study of the Haitian Earthquake. World Medical \& Health Policy 2010. 2(2).

2. Abbasi, A., et al., Social Networks Perspective of Firefighters' Adaptive Behaviour and Coordination among Them, in Proceedings of the 2010 IEEE/ACM Int'l Conference on Green Computing and Communications \& Int'l Conference on Cyber, Physical and Social Computing. 2010, IEEE Computer Society. p. 819-824.

3. Durham, T.S., P. Johari, and D. Bausch, Strategic directions in seismic modeling: HAZUS® development and current applications for catastrophe planning in Risk Assessment, modeling and decision support: strategic directions A. Bostrom, S. French, and S. Gottlieb, Editors. 2008, Heidelberg: Springer - Verlag Berlin p. 101-116.

4. Vieweg, S., et al., Microblogging during two natural hazards events: what twitter may contribute to situational awareness, in The 28th international conference on Human factors in computing systems Atlanta: Association of Computing Machienry. 2010. p. 1079 1088 . 
5. Nazarian, E., et al., Machine-learning-based approach for post event assessment of damage in a turn-of-the-century building structure. Journal of Civil Structural Health Monitoring, 2018. 8(2): p. 237-251.

6. Gonzalez-Drigo, R., et al., Assessment of Post-Earthquake Damaged Building with Interferometric Real Aperture Radar. Remote Sensing, 2019. 11(23): p. 2830.

7. Contreras, D., Fuzzy Boundaries Between Post-Disaster Phases: The Case of L'Aquila, Italy. International Journal of Disaster Risk Science, 2016. 7(3): p. 277-292.

8. Wartman, J., et al., Research Needs, Challenges, and Strategic Approaches for Natural Hazards and Disaster Reconnaissance. Frontiers in Built Environment, 2020. 6: p. 17.

9. Farrar, C.R. and K. Worden, An introduction to structural health monitoring. Philosophical Transactions of the Royal Society A: Mathematical, Physical and Engineering Sciences, 2007. 365(1851): p. 303-315.

10. Miura, H., S. Midorikawa, and M. Matsuoka, Building Damage Assessment Using High-Resolution Satellite SAR Images of the 2010 Haiti Earthquake. Earthquake Spectra, 2016. 32(1): p. 591-610.

11. Stannard, M., et al., Field guide: Rapid Post Disaster building usability assessment - earthquakes. 2014, Wellington: Ministry of Business, Innovation and Employment.

12. Contreras, D., G. Forino, and T. Blaschke, Measuring the progress of a recovery process after an earthquake: The case of L'Aquila, Italy. International Journal of Disaster Risk Reduction, 2018. 28: p. 450-464.

13. Matsuoka, M. and F. Yamazaki, Use of Satellite SAR Intensity Imagery for Detecting Building Areas Damaged Due to Earthquakes. Earthquake Spectra - EARTHQ SPECTRA, 2004. 20.

14. Contreras, D., T. Blaschke, and M.E. Hodgson, Lack of spatial resilience in a recovery process: Case L'Aquila, Italy. Technological Forecasting and Social Change, 2017. 121: p. 76-88.

15. Sharma, R.C., et al., Earthquake Damage Visualization (EDV) Technique for the Rapid Detection of Earthquake-Induced Damages Using SAR Data. Sensors, 2017. 17(2): p. 235.

16. Bossu, R., et al., LastQuake: From rapid information to global seismic risk reduction. International Journal of Disaster Risk Reduction, 2018. 28: p. 32-42.

17. Dong, L. and J. Shan, A comprehensive review of earthquake-induced building damage detection with remote sensing techniques. Vol. 84. 2013. 85-99.

18. Fan, Y.D., et al., Quantifying Disaster Physical Damage Using Remote Sensing Data-A Technical Work Flow and Case Study of the 2014 Ludian Earthquake in China. International Journal of Disaster Risk Science, 2017. 8(4): p. 471-488.

19. Li, L., et al., Building damage assessment from PolSAR data using texture parameters of statistical model. Computers \& Geosciences, 2018. 113: p. 115-126.

20. Contreras, D., et al., Myths and realities about the recovery of L'Aquila after the earthquake. International Journal of Disaster Risk Reduction, 2014. 8(0): p. 125-142.

21. Cusicanqui, J., N. Kerle, and F. Nex, Usability of aerial video footage for 3-D scene reconstruction and structural damage assessment. Natural Hazards and Earth System Sciences, 2018. 18(6): p. 1583-1598.

Qadir, J., et al., Crisis analytics: big data-driven crisis response. Journal of International Humanitarian Action, 2016.1 (1): p. 12. Ragini, J.R., P.M.R. Anand, and V. Bhaskar, Big data analytics for disaster response and recovery through sentiment analysis. International Journal of Information Management, 2018. 42: p. 13-24.

24. Foulser-Piggott, R., et al., Using Remote Sensing for Building Damage Assessment: GEOCAN Study and Validation for 2011 Christchurch Earthquake. Earthquake Spectra, 2016. 32(1): p. 611-631.

25. Zhou, Z. and J. Gong, Automated Analysis of Mobile LiDAR Data for Component-Level Damage Assessment of Building Structures during Large Coastal Storm Events. Computer-Aided Civil and Infrastructure Engineering, 2018. 33(5): p. $373-392$.

26. Rossetto, T., et al., The value of multiple earthquake missions: the EEFIT L'Aquila Earthquake experience. Bulletin of Earthquake Engineering, 2014. 12(1): p. 277-305. 
27. Galvis, F.A., et al., Overview of collapsed buildings in Mexico City after the 19 September 2017 (M(w)7.1) earthquake. Earthquake Spectra, 2020.36(2_SUPPL): p. 83-109.

28. Lan, Y.J., et al., ATC Mw7.1 Puebla-Morelos earthquake reconnaissance observations: Structural observations and instrumentation. Earthquake Spectra, 2020. 36(2_suppl): p. 31-48.

29. Roeslin, S., et al., The September 19th, 2017 Puebla, Mexico earthquake: final report of the New Zealand Reconnaissance Team. Bulletin of the New Zealand Society for Earthquake Engineering, 2020. 53(3): p. 150-172.

30. Mangalathu, S. and H. Burton, Deep learning-based classification of earthquake-impacted buildings using textual damage descriptions. International Journal of Disaster Risk Reduction, 2019. 36: p. 101111.

31. Franke, K.W., et al., Phased Reconnaissance Approach to Documenting Landslides Following the 2016 Central Italy Earthquakes. Earthquake Spectra, 2018. 34(4): p. 1693-1719.

32. Mazzoni, S., et al., 2016-2017 Central Italy Earthquake Sequence: Seismic Retrofit Policy and Effectiveness. Earthquake Spectra, 2018. 34(4): p. 1671-1691.

33. Xu, Z., et al., A smart phone-based system for post-earthquake investigations of building damage. International Journal of Disaster Risk Reduction, 2018. 27: p. 214-222.

34. Stone, H., V. Putrino, and D. D'Ayala, Earthquake Damage Data Collection Using Omnidirectional Imagery. Frontiers in Built Environment, 2018. 4: p. 14.

35. Hess, M., et al., Terrestrial laser scanning for the comprehensive structural health assessment of the Baptistery di San Giovanni in Florence, Italy: an integrative methodology for repeatable data acquisition, visualization and analysis. Structure and Infrastructure Engineering, 2018. 14(2): p. 247-263.

36. Contreras, D., et al., Monitoring recovery after earthquakes through the integration of remote sensing, GIS, and ground observations: the case of L'Aquila (Italy). Cartography and Geographic Information Science, 2016. 43(2): p. 115-133.

37. Fytsilis, A.L., et al., A methodology for near real-time change detection between Unmanned Aerial Vehicle and wide area satellite images. ISPRS Journal of Photogrammetry and Remote Sensing, 2016. 119: p. 165-186.

38. Nex, F. and F. Remondino, UAV for 3D mapping applications: a review. Applied Geomatics, 2014. 6(1): p. 1-15.

39. Bai, Y., et al., Building Damage Assessment in the 2015 Gorkha, Nepal, Earthquake Using Only Post-Event Dual Polarization Synthetic Aperture Radar Imagery. Vol. 33. 2017.

40. Parker, A.L., M.S. Filmer, and W.E. Featherstone, First Results from Sentinel-1A InSAR over Australia: Application to the Perth Basin. Remote Sensing, 2017. 9(3): p. 19.

41. Sreejith, K.M., et al., Coseismic and early postseismic deformation due to the 25 April 2015, Mw 7.8 Gorkha, Nepal, earthquake from InSAR and GPS measurements. Geophysical Research Letters, 2016. 43(7): p. 3160-3168.

42. Diao, F., et al., The 2015 Gorkha earthquake investigated from radar satellites: slip and stress modeling along the MHT. Frontiers in Earth Science, 2015. 3(65).

43. Grandin, R., et al., Rupture process of the $M w=7.92015$ Gorkha earthquake (Nepal): Insights into Himalayan megathrust segmentation. Geophysical Research Letters, 2015. 42(20): p. 8373-8382.

44. Quitoriano, V. and D.J. Wald, USGS "Did You Feel It?"-Science and Lessons From 20 Years of Citizen Science-Based Macroseismology. Frontiers in Earth Science, 2020. 8(120).

45. Finazzi, F., The Earthquake Network Project: A Platform for Earthquake Early Warning, Rapid Impact Assessment, and Search and Rescue. Frontiers in Earth Science, 2020. 8(243).

46. Bossu, R., et al., Rapid Public Information and Situational Awareness After the November 26, 2019, Albania Earthquake: Lessons Learned From the LastQuake System. Frontiers in Earth Science, 2020. 8(235): p. 1-15.

47. Kong, Q.K., R. Martin-Short, and R.M. Allen, Toward Global Earthquake Early Warning with the MyShake Smartphone Seismic Network, Part 2: Understanding MyShake Performance around the World. Seismological Research Letters, 2020. 91(4): p. 22182233. 
48. Subedi, S., et al., Seismology at School in Nepal: A Program for Educational and Citizen Seismology Through a Low-Cost Seismic Network. Frontiers in Earth Science, 2020. 8: p. 19.

49. Zhao, R., X.T. Liu, and W.B. Xu, Integration of coseismic deformation into WebGIS for near real-time disaster evaluation and emergency response. Environmental Earth Sciences, 2020. 79(18): p. 11.

50. Liang, W.T., J.C. Lee, and N.C. Hsiao, Crowdsourcing Platform Toward Seismic Disaster Reduction: The Taiwan Scientific Earthquake Reporting (TSER) System. Frontiers in Earth Science, 2019. 7: p. 12.

51. Fallou, L., et al., Citizen Seismology Without Seismologists? Lessons Learned From Mayotte Leading to Improved Collaboration. Frontiers in Communication, 2020. 5(49): p. 1-17.

52. Lacassin, R., et al., Rapid collaborative knowledge building via Twitter after significant geohazard events. Geosci. Commun., 2020. 3(1): p. 129-146.

53. Kropivnitskaya, Y., et al., The Predictive Relationship between Earthquake Intensity and Tweets Rate for Real - Time Ground Motion Estimation. Seismological Research Letters, 2017. 88: p. 840-850.

54. Kropivnitskaya, Y., et al., Real-Time Earthquake Intensity Estimation Using Streaming Data Analysis of Social and Physical Sensors. Pure and Applied Geophysics, 2017. 174(6): p. 2331-2349.

55. Carvajal, M., et al., Nearly Instantaneous Tsunamis Following the Mw 7.5 2018 Palu Earthquake. Geophysical Research Letters, 2019. 46(10): p. 5117-5126.

56. Chu, E.T.H. and C.C. Wu, An image-based seismic damage assessment system. Multimedia Tools and Applications, 2016. 75(3): p. 1721-1743.

57. Freddi, F., et al., Observations from the 26th November 2019 Albania earthquake: the earthquake engineering field investigation team (EEFIT) mission. Bulletin of Earthquake Engineering, 2021.

58. Chian, S.C., et al., Lessons Learnt From the 2009 Padang Indonesia, 2011 Tōhoku Japan and 2016 Muisne Ecuador Earthquakes. Frontiers in Built Environment, 2019. 5(73).

59. De Luca, F., et al., RC infilled building performance against the evidence of the 2016 EEFIT Central Italy post-earthquake reconnaissance mission: empirical fragilities and comparison with the FAST method. Bulletin of Earthquake Engineering, 2018. 16(7): p. 2943-2969.

60. Friedland, C.J., Residential building damage from hurricane storm surge: proposed methodologies to describe, assess and model building damage, in Civil and Environmental Engineering Commons. 2009, Louisiana State University. p. 2015.

61. Wilkinson, S., C.K. Huyck, and T. Rossetto, Editorial: Earthquake Reconnaissance - Building the Risk and Resilience Evidence Base. Frontiers in Built Environment, 2020. 6(55).

62. Goda, K., et al., The 2016 Kumamoto Earthquakes: Cascading Geological Hazards and Compounding Risks. Frontiers in Built Environment, 2016. 2(19).

63. Freeman, M., et al., Sequential Earthquake Damage Assessment Incorporating Optimized sUAV Remote Sensing at Pescara del Tronto. Geosciences, 2019. 9(8): p. 24.

64. Wilkinson, S., et al., EEFIT Mission report: The Christchurch New Zealand Earthquake of 22 February 2011. 2011, EEFIT. p. 123.

65. Wilson, J., et al., Assessing the Built Environment Using Omnidirectional Imagery. American journal of preventive medicine, 2012. 42: p. 193-9.

66. Nguyen, Q.C., et al., Using Google Street View to examine associations between built environment characteristics and U.S. health outcomes. Preventive Medicine Reports, 2019. 14: p. 100859.

67. Berland, A. and D.A. Lange, Google Street View shows promise for virtual street tree surveys. Urban Forestry \& Urban Greening, 2017. 21: p. 11-15.

68. Lemmens, M., Terrestrial laser scanning. Geoinformation. 2011: Springer.

69. FARO. Laser Scanner FARO Focus3D - Overview - 3D Surveying. 2017 [cited 2017 The 19th January 2017]; Available from: http://www.faro.com/en-us/products/3d-surveying/faro-focus3d/overview. 
70. FARO. FARO FOCUS X330. 2019 [cited 2019 The 29th October 2019]; Available from: https://manchestermetrology.co.uk/equipment-hire/1082-2/?gclid=CjwKCAjwxt_tBRAXEiwAENY8hfSbKsKfdOIRGIdkd28yLugEKWYAhFjLJQxenZVVwKV3351SZApFRoCVMQQAvD_BwE.

71. Rathje, E.M. and B.J. Adams, The Role of Remote Sensing in Earthquake Science and Engineering: Opportunities and Challenges. Earthquake Spectra, 2008. 24(2): p. 471-492.

72. Dai, K., et al., Surface damage quantification of postearthquake building based on terrestrial laser scan data. Structural Control and Health Monitoring, 2018. 25(8): p. e2210.

73. Zhou, Z., J. Gong, and X. Hu, Community-scale multi-level post-hurricane damage assessment of residential buildings using multitemporal airborne LiDAR data. Automation in Construction, 2019. 98: p. 30-45.

74. Stimson, G.W., Introduction to Airborne Radar (2nd Edition). SciTech Publishing.

75. López-Martínez, C. and E. Pottier, Basic Principles of SAR Polarimetry, in Polarimetric Synthetic Aperture Radar. Principles and application., I. Hajnsek and Y.-L. Desnos, Editors. 2021, Springer. p. 1-58.

76. S. Tallett-Williams, B.G., S. Wilkinson, C. Fenton, P. Burton, M. Whitworth, S. Datla, G. Franco, A. Trieu, M. Dejong, V. Novellis, T. White, and T. Lloyd., Site amplification in the Kathmandu Valley during the 2015 M7.6 Gorkha, Nepal earthquake. Bulletin of Earthquake Engineering 2016. 14(12).

77. Australia. Interferometric Synthetic Aperture Radar. 2021 [cited 2021; Available from: https://www.ga.gov.au/scientifictopics/positioning-navigation/geodesy/geodetic-techniques/interferometric-synthetic-aperture-radar.

78. Helz, R.L. InSAR-Satellite-based technique captures overall deformation "picture". Volcano Hazards Program 2021 [cited 2021 The 10th August 2021]; Available from: https://www.usgs.gov/natural-hazards/volcano-hazards/insar-satellite-basedtechnique-captures-overall-deformation-picture.

79. Fielding, E.J., et al., Surface ruptures and building damage of the 2003 Bam, Iran, earthquake mapped by satellite synthetic aperture radar interferometric correlation. Journal of Geophysical Research: Solid Earth, 2005. 110(B3).

80. Elliott, J.R., et al., Himalayan megathrust geometry and relation to topography revealed by the Gorkha earthquake. Nature Geoscience, 2016. 9(2): p. 174-180.

81. Ghazoui, Z., et al., Potentially large post-1505 AD earthquakes in western Nepal revealed by a lake sediment record. Nature Communications, 2019. 10(1): p. 2258.

82. Ambraseys, N. and D. Jackson, A note on early earthquakes in northern India and southern Tibet. Current science(Bangalore), 2003. 84: p. 570-582.

83. Okada, Y., Internal Deformation due to shear and tensile faults in a half-space Bulletin of the Seismological Society of America, 1992. 82(2): p. 1018-1040.

84. Ushahidi. About Ushaidi. 2021 [cited 2021 The 130821]; Available from: https://www.ushahidi.com/about.

85. Veil, S.R., T. Buehner, and M.J. Palenchar, A Work-In-Process Literature Review: Incorporating Social Media in Risk and Crisis Communication. Journal of Contingencies and Crisis Management, 2011. 19(2): p. 110-122.

86. Yan, Y., J. Chen, and Z. Wang, Mining public sentiments and perspectives from geotagged social media data for appraising the postearthquake recovery of tourism destinations. Applied Geography, 2020. 123: p. 102306.

87. Kryvasheyeu, Y., et al., Performance of Social Network Sensors during Hurricane Sandy. PLOS ONE, 2015. 10(2): p. e0117288.

88. Murakami, A. and T. Nasukawa, Tweeting about the tsunami?: mining twitter for information on the tohoku earthquake and tsunami, in Proceedings of the 21st International Conference on World Wide Web. 2012, ACM: Lyon, France. p. 709-710.

89. Doan, S., B.-K.H. Vo, and N. Collier. An Analysis of Twitter Messages in the 2011 Tohoku Earthquake. 2012. Berlin, Heidelberg: Springer Berlin Heidelberg.

90. Fritz, H., et al., 2004 Indian Ocean tsunami flow velocity measurements from survivor videos. Geophysical Research Letters GEOPHYS RES LETT, 2006. 332. 
91. Koshimura, S. and S. Hayashi, Tsunami flow measurement using the video recorded during the 2011 Tohoku tsunami attack, in IEEE International Geoscience and Remote Sensing Symposium 2012: Munich, Germany. p. 6693-6696.

92. Booth, E., et al. EEFIT: The UK earthquake engineering field investigation team. 2011.

93. Mangalathu, S. and H. Burton, Deep learning-based classification of earthquake-impacted buildings using textual damage descriptions. Vol. 36. 2019. 101111.

94. Contreras, D. Designing a spatial planning support system for rapid building damage survey after an earthquake: the case of Bogotá D.C., Colombia. in URISA 2009 Annual Conference. 2009. Anaheim, California (USA).

95. What3 words. 2021 [cited 2021 The 18 May 2021]; Available from: https://what3words.com/suene.madera.granja.

96. Papapesios, N., et al., Exploring the use of crowdsourced geographic information in defence: challenges and opportunities. Journal of Geographical Systems, 2019. 21(1): p. 133-160.

97. Yan, Y., et al., Monitoring and Assessing Post-Disaster Tourism Recovery Using Geotagged Social Media Data. ISPRS International Journal of Geo-Information, 2017. 6(5): p. 144.

98. Cervone, G., et al., Using Twitter for tasking remote-sensing data collection and damage assessment: 2013 Boulder flood case study. International Journal of Remote Sensing, 2016. 37(1): p. 100-124.

99. Raspberry. Our story 2021 [cited 2021 The 30th July 2021]; Available from: https://raspberryshake.org/about/our-story/.

100. Al-Nammari, F.M. and M.K. Lindell, Earthquake recovery of historic buildings: exploring cost and time needs. Disasters, 2009. 33(3): p. 457-481.

101. Cervone, G. and C. Hultquist. Citizen as indispensable sensors during disasters. in Population-environment research network cybeseminar, people and pixels revisited. 2018. 